\title{
EL RÉGIMEN JURÍDICO DE LAS COSTAS. ESPECIAL REFERENCIA A LA REFORMA DE LA LEY DE COSTAS A LA LUZ DE LA JURISPRUDENCIA DEL TRIBUNAL CONSTITUCIONAL MÁS RECIENTE
}

\author{
MARINA RODRÍGUEZ BEAS \\ Profesora contratada de Derecho Administrativo \\ Universitat Rovira i Virgili \\ marina.rodriguez@urv.cat
}

Recibido: 12 de abril de 2016 / Aceptado: 31 de mayo de 2016

RESUMEN: La Ley 2/2013, de 29 de mayo, de protección y uso sostenible del litoral y modificación de la Ley 22/1988, de 28 de julio, de Costas, supone la mayor reforma de la Ley de Costas desde su aprobación en 1988, introduciendo cambios sustanciales que afectan al régimen jurídico de la costa.

El nuevo texto articulado de la Ley de Costas prevé mecanismos que plantean dudas razonables de constitucionalidad. Dudas tanto desde la perspectiva de nuevas invasiones competenciales en relación con las competencias autonómicas en materia de ordenación del litoral y medio ambiente y de los entes locales en materia de autonomía municipal como desde la perspectiva de la reducción del espacio protegido del dominio público marítimo-terrestre. Se trata, en definitiva, de una norma controvertida que está teniendo un fuerte impacto en el régimen de la costa y que, por ello, ha sido recurrida desde varias instancias ante el Tribunal Constitucional.

En este trabajo se abordan dichas dudas sobre las cuestiones más polémicas a la luz de los recientes pronunciamientos del Tribunal Constitucional sobre la reforma de la Ley de Costas.

RESUM: La Llei 2/2013, de 29 de maig, de protecció i ús sostenible del litoral i modificació de la Llei 22/1988, de 28 de juliol, de costes, suposa la major reforma de la Llei de Costes des de la seva aprovació l'any 1988, introduint canvis substancials que 
afecten el règim jurídic de la costa.

El nou text articulat de la Llei de Costes preveu mecanismes que plantegen dubtes raonables de constitucionalitat. Dubtes tant des de la perspectiva de noves invasions competencials en relació amb les competències autonòmiques en matèria d'ordenació del litoral i medi ambient i dels ens locals en matèria d'autonomia municipal com des de la perspectiva de la reducció de l'espai protegit del domini públic marítim-terrestre. Es tracta, en definitiva, d'una norma controvertida que està tenint un fort impacte en el règim de la costa, i per això, ha estat recorreguda des de diverses instàncies davant del Tribunal Constitucional.

En aquest treball s'aborden aquests dubtes sobre les qüestions més polèmiques a la llum dels recents pronunciaments del Tribunal Constitucional sobre la reforma de la Llei de Costes.

ABSTRACT: Act 2/2013, May 29, on the Protection and Sustainable Use of Coastline, and the modification of the Coastal Act 22/1988, July 28, 1988, is the biggest reform of the Coastal Act since its adoption in 1988. It introduces substantial changes that affect the legal status of the coast.

The new articled text of the Coastal Act provides mechanisms that raise reasonable doubts about constitutionality. These doubts arise not only from the perspective of new encroachments into the regional competencies for coastal and environmental management and the competencies of the local authorities on issues of municipal autonomy but also from the perspective of the reduction in the protected area of the maritime-terrestrial public domain. In short, it is a controversial ruling that is having a considerable impact on the coastal regime, and therefore numerous appeals have been filed in the Constitutional Court.

This study focuses on the most controversial of these doubts in the light of the recent rulings of the Constitutional Court on the reform of the Coastal Act.

PALABRAS CLAVE: Distribución de competencias - Dominio público marítimoterrestre - Servidumbre - Ordenación del territorio - Urbanismo - Medio ambiente. 
PARAULES CLAU: Distribució de competències — Domini públic marítim terrestre — Servitud — Ordenació del territori — Urbanisme — Medi ambient.

KEYWORDS: Distribution of powers - Maritime-terrestrial public domain Servitude — Regional planning — City planning — Environment.

Sumario: I. Introducción. II. El sistema de distribución de competencias: el problema de la concurrencia de competencias sobre la zona costa. III. El alcance de las competencias administrativas en la Ley de Costas. 1. Las competencias de la Administración del Estado. 2. Las competencias de las comunidades autónomas. 3. Las competencias de los municipios sobre su litoral. 3.1. La suspensión de actos y acuerdos adoptados por las entidades locales. IV. La demanialidad: instrumento esencial de protección de las costas. 1. La delimitación de los bienes que forman parte del dominio público marítimo-terrestre: la exclusión de determinados bienes de la ribera del mar. 1.1. La zona marítimo-terrestre. 1.2. Las playas. 1.3. Los terrenos cuya superficie sea invadida por el mar. 1.4. Los supuestos singulares. V. Mecanismos para proteger los bienes que forman parte del dominio público. 1. Limitaciones al derecho de propiedad sobre los terrenos adyacentes a la ribera del mar. 1.1. Conjunto de limitaciones y servidumbres. A. La servidumbre de protección. 1.2. Determinadas reglas para la ocupación del dominio público marítimoterrestre. VI. Conclusiones. VII. Bibliografía.

\section{INTRODUCCIÓN}

La zona costera constituye un patrimonio ambiental único, con unos recursos ecológicos, culturales y económicos de gran importancia. Pero está sujeta a una demanda de uso y explotación muy intensa. Estas tensiones entre las demandas de uso público y la necesidad ineludible de protección medioambiental de las costas han supuesto que esta materia sea objeto destacado de regulación jurídica y tutela administrativa.

El derecho de costas en España se contiene, fundamentalmente, en la Ley 22/1988, de 28 de junio, de Costas (LC), y en el Real Decreto 876/2014, de 10 de octubre, por el que se aprueba el Reglamento General de Costas (RGC). El carácter básico de dicha legislación legitima la protección y defensa del litoral por parte del Estado. Pese a los diferentes intentos por reformar dicha legislación básica, esta ha gozado de gran estabilidad hasta fechas muy recientes, cuando ha sufrido una modificación sustancial mediante la Ley 2/2013, de 29 de mayo, de protección y uso sostenible del litoral y de modificación de la LC (LPUSL).

La citada LC nace, en esencia, como una reacción ante los usos y la falta de una legislación adecuada en la franja litoral. Como señala su exposición de motivos, se ha 
llegado a una situación de degradación de la zona por diversos motivos, pero entre ellos por actuaciones inconexas, "sin la necesaria coordinación entre la legislación del dominio público marítimo y la del suelo, sin tener en cuenta la interacción tierra-mar, ni la necesidad de establecer medidas que garanticen la conservación de estos espacios singularmente sensibles al deterioro, ni los costes externos a la propia acción ni la rentabilidad o valor social del medio".

La LC contempla un amplio abanico de técnicas de intervención administrativa cuya finalidad última es la protección del patrimonio costero para asegurar su integridad y adecuada conservación, así como la utilización racional de los bienes que lo integran ${ }^{1}$. Sin embargo, a pesar de su incuestionable carácter proteccionista, la práctica ha demostrado la dificultad de su viabilidad. Esta ley reclama una fuerte intervención de las administraciones públicas competentes, si bien no siempre ha encontrado respuesta. Así, la LC presentaba disfunciones derivadas, básicamente, de tres elementos: un texto excesivamente uniformizador para un litoral complejo como el nuestro; un régimen transitorio excesivamente amplio; y probablemente una falta de rigor en su aplicación ${ }^{2}$.

En este sentido, el propio preámbulo de la LPUSL muestra la litigiosidad "crónica" en cuestiones relacionadas con el régimen competencial y el derecho de propiedad que ha provocado la LC desde su aprobación ${ }^{3}$.

Sin embargo, la reforma de la LC, amparándose en la necesidad de garantizar la protección del litoral y otorgar más seguridad jurídica, y con un título aparentemente más proteccionista de lo que en realidad es, paradójicamente hace lo contrario al reducir el ámbito de protección de la LC.

Entre otros cambios, que a continuación se analizan, la reforma redefine parcialmente el dominio público marítimo-terrestre al introducir nuevos criterios que afectan a los

\footnotetext{
${ }^{1}$ Para un estudio exhaustivo sobre la protección y ordenación de las costas, vid. BLASCO DÍAZ, J. L., Régimen jurídico de las propiedades particulares en el litoral, Tirant lo Blanch, Valencia, 1999.

${ }^{2}$ AGUIRRE I FONT, J. M., “L'impacte de la reforma de la Llei de costes sobre el règim jurídic del litoral català: especial referència a la reducció de l'espai protegit i a les invasions competencials", Revista catalana de dret públic, núm. 47, 2013, p. 142. No obstante, paradójicamente, esta norma fue mencionada en el Informe del Parlamento Europeo de 20 de febrero de 2009, conocido como Informe Auken, en el que, al analizar el urbanismo salvaje, insta a las autoridades españolas a que revisen y modifiquen la LC a fin de proteger los derechos legítimos de los propietarios de viviendas en la costa.

${ }^{3}$ Como se reconoce en el mismo preámbulo de la LPUSL, "en no pocos supuestos, ni siquiera ha llegado a aplicarse, tolerándose situaciones inaceptables medioambientalmente que aún no han sido resueltas. Tanto la aplicación conflictiva como la inaplicación o incluso la impotencia de la norma para imponerse sobre realidades sociales consolidadas son la prueba de que aquella concepción debe ser corregida".
} 
deslindes; establece una distinción entre playas naturales y playas urbanas; y modifica el régimen de utilización y ocupación del litoral introduciendo una nueva prórroga extraordinaria de las concesiones para los enclaves situados en el dominio público, ampliando el plazo de vigencia de estas autorizaciones y concesiones, permitiendo la transmisión inter vivos de viviendas situadas en dominio público y autorizando nuevas actividades en la cosa. Igualmente, introduce modificaciones que afectan a las servidumbres de tránsito y de protección, estableciendo un régimen más flexible para las obras de renovación y mejora en edificaciones situadas en este espacio, y ampliando los supuestos excepcionales en que puede disminuirse la anchura de dichas servidumbres. Todo ello, sin olvidar que dicha reforma vuelve a cuestionar las competencias autonómicas y locales en materia costera.

\section{EL SISTEMA DE DISTRIBUCIÓN DE COMPETENCIAS: EL PROBLEMA DE LA CONCURRENCIA DE COMPETENCIAS SOBRE LA ZONA COSTA}

Teniendo en cuenta la concurrencia de competencias que se produce sobre el espacio litoral, debemos realizar una aproximación al ámbito competencial que corresponde a las diferentes administraciones públicas actuantes — estatal, autonómica y local— ${ }^{4}$.

El Estado es titular del dominio público marítimo-terrestre. No obstante, de acuerdo con la doctrina recogida en la Sentencia del Tribunal Constitucional (STC) 149/1991, de 4 de julio $^{5}$, la titularidad estatal sobre el dominio público marítimo-terrestre no habilita como título atributivo de competencias, si bien ex artículo 132.2 Constitución española (CE), en relación con el artículo 149.1.1 y 8 CE, reconoce como competencia propia del Estado la de definir el dominio público estatal y establecer el régimen jurídico de los bienes que lo integran y, como parte de este, las medidas destinadas a su protección ${ }^{6}$.

\footnotetext{
${ }^{4}$ Para un estudio más exhaustivo, véase BLASCO DÍAZ, J. L., "La distribución competencial en materia de costas”, Revista d'Estudis Autonòmics i Federals, núm. 10, 2010, pp. 245-285.

${ }^{5}$ Esta Sentencia del TC resuelve los recursos de inconstitucionalidad 1689/1988, 1708/1988, 1711/1988, 1715/1988, 1717/1988, 1723/2988, 1728/1988, 1729/1988 y 1740/1988 interpuestos por la Xunta de Galicia, el Consejo de Gobierno de las Islas Baleares, el Gobierno Vasco, el Parlamento de Cataluña, el Consejo de Gobierno de la Diputación Regional de Cantabria, el Consejo Ejecutivo de la Generalitat de Cataluña, el Gobierno de Canarias, el Gobierno de Valencia y un grupo de 50 diputados contra la LC y anula alguno de sus preceptos por considerar que vulneran el orden constitucional y estatutario de distribución de competencias. En este pronunciamiento, se trata con todo detalle el encuadramiento general de la controversia desde su dimensión competencial.

${ }^{6} \mathrm{El} \mathrm{TC}$ ha abordado en profundidad las distintas facetas del régimen constitucional del dominio público marítimo-terrestre. La doctrina está recogida tanto en la STC 149/1991, de 4 de julio, que enjuició la LC,
} 
Este régimen de protección del dominio público marítimo-terrestre se traduce en la imposición de límites y condicionantes que entran en directa confrontación con las competencias autonómicas en materia de ordenación del territorio. Ahora bien, como señala el Tribunal Constitucional, la titularidad estatal no debe "condicionar abusivamente la utilización de competencias ajenas, en particular la de ordenación del territorio propia de las Comunidades Autónomas" (STC 149/1991).

Además de estas facultades que pueden derivarse de la titularidad del dominio público marítimo-terrestre, el Estado dispone de otros títulos competenciales que podrían legitimar su actuación: con carácter general, los enunciados en los apartados 1 (“Condiciones básicas que garanticen la igualdad de todos los españoles en el ejercicio de los derechos y en el cumplimiento de los deberes constitucionales") y 23 ("Legislación básica sobre protección del medio ambiente") del artículo 149.1 CE. Pero los citados preceptos no agotan las posibilidades de intervención del Estado en el litoral, sino que existen otras competencias sectoriales que legitiman la acción normativa e incluso ejecutiva del Estado en supuestos determinados (apartados 4 -Defensa-, 8 Legislación civil—, 13 -Planificación general de la actividad económica—, 20 Marina mercante, iluminación de costas y señales marítimas, puertos de interés general-, 21 - Transportes, comunicaciones- o 24 -Obras públicas de interés general o cuya realización afecte a más de una Comunidad Autónoma- del artículo 149.1 CE).

Desde la perspectiva autonómica, el título competencial que con mayor intensidad se proyecta sobre el litoral es precisamente el de ordenación del territorio y urbanismo ${ }^{7}$. Este título ha sido utilizado por todos los estatutos de autonomía, que asignan a las comunidades autónomas la competencia con carácter exclusivo ${ }^{8}$.

como en la STC 233/2015, de 5 de noviembre, que se ocupa de enjuiciar la LPUSL, así como en las más recientes SSTC 6/2016, de 21 de enero, y 28/2016, de 18 de febrero, en las que se remite a los pronunciamientos previos citados.

${ }^{7}$ Este título competencial ha sido objeto de un amplio análisis en las SSTC 61/1997, de 20 de marzo, y 46/2007, de 1 de marzo, teniendo en cuenta que, para la jurisprudencia constitucional, la ordenación del litoral no constituye una materia distinta, sino una manifestación de la ordenación del territorio caracterizada por la singularidad del espacio sobre el que se proyecta.

${ }^{8}$ En este sentido, el Estatuto de Autonomía de Cataluña (EAC) atribuye de forma exclusiva a la Generalitat las competencias en materia de ordenación del territorio y del paisaje, la de ordenación del litoral, que incluye la ejecución y gestión de las obras costeras de interés general, y todas las urbanísticas. Pero, a pesar de este contenido estatutario, la STC 31/2010, de 28 de junio, interpretó el alcance del concepto de competencia exclusiva en los siguientes términos: "[...] el art. 110 EAC no es contrario a la Constitución en tanto que aplicable a supuestos de competencia material plena de la Comunidad 
Pero junto a este título competencial, las comunidades autónomas también disponen de competencias propias en materia de medio ambiente, espacios naturales protegidos, puertos o protección del patrimonio histórico-artístico, entre otras.

Las relaciones entre la ordenación del territorio y el urbanismo y las políticas sectoriales del Estado parten de la necesaria integración de las previsiones contenidas en los planteamientos sectoriales estatales en los instrumentos de planificación territorial, y del ejercicio por la comunidad autónoma de su competencia de forma que no vulnere las competencias sectoriales. En este sentido, la STC 46/2007, de 1 de marzo, señala lo siguiente: “[...] el ejercicio de la competencia autonómica sobre ordenación del litoral no puede a su vez reducir el contenido de las facultades que corresponden al Estado en cuanto titular del dominio público marítimo terrestre, entre las que se encuentra la definición de los criterios para determinar los bienes integrantes de dicho dominio público y la delimitación concreta de tales bienes, con el alcance determinado en la STC 149/1991, de 4 de julio, FJ. 2”.

Finalmente, los municipios también tienen un cierto protagonismo sobre el dominio marítimo. En efecto, aunque la CE no explicita las competencias municipales, garantiza la autonomía para la gestión de sus intereses (arts. 137 y $140 \mathrm{CE}$ ). En el caso de Cataluña, el artículo 84.2 n) EAC incluye entre las competencias propias de los gobiernos locales de Cataluña "la regulación, la gestión y la vigilancia de las actividades y los usos que se llevan a cabo en las playas, los ríos, los lagos y la montaña"9.

En definitiva, nos encontramos con tres administraciones territoriales -Estado, comunidades autónomas y entes locales - que ostentan competencias con diferente

Autónoma y en cuanto no impide el ejercicio de las competencias exclusivas del Estado ex art. 149.1 CE, sea cuando éstas concurren con las autonómicas sobre el mismo espacio físico u objeto jurídico, sea cuando se trate de materias de competencia compartida, cualquiera que sea la utilización de los términos 'competencia exclusiva' o 'competencias exclusivas' en los restantes preceptos del Estatuto, sin que tampoco la expresión 'en todo caso' reiterada en el Estatuto respecto de ámbitos competenciales autonómicos, tenga otra virtualidad que la meramente descriptiva ni impida, por sí sola, el pleno y efectivo ejercicio de las competencias estatales [...]". Sobre la delimitación de las competencias en el EAC, de acuerdo con la interpretación reduccionista y restrictiva al máximo de la autonomía en la STC 31/2010, vid. TORNOS MAS, J., "Tipologia de les competències. El seu abast funcional: els articles 110 a 112", Revista catalana de dret públic. Especial Sentència 31/2010 del Tribunal Constitucional, sobre l'Estatut d'Autonomia de Catalunya de 2006, 2010, pp. 288-294.

${ }^{9}$ Vid., in totum, RODRÍGUEZ BEAS, M. y FUENTES I GASÓ, J. R., "La organización territorial del Estatuto de 2006 y el impacto de la Ley 27/2013, de Racionalización y Sostenibilidad de la Administración Local en la interiorización del régimen local de Cataluña", García Rubio, F. (dir.), Análisis de las repercusiones de la reforma local sobre la organización, competencias y servicios de las entidades locales, INAP Investiga, Madrid, 2015, pp. 511-568. 
objeto jurídico pero que concurren sobre un mismo espacio físico, con la dificultad de coordinación de actuaciones que este hecho plantea.

Los títulos competenciales que utilizó el legislador para aprobar la LC fueron el 132.2 $\mathrm{CE}$, que atribuye al Estado la titularidad del dominio público marítimo-terrestre, y el 45 $\mathrm{CE}$, que garantiza el derecho a un medio ambiente adecuado y obliga a los poderes públicos a preservarlo. De este modo, el legislador estatal necesariamente ha de partir de las realidades naturales que la CE marca en el artículo $132 \mathrm{CE}$, y al definir tales realidades naturales no puede acudir a criterios irracionales y caprichosos. Así, como ha destacado el TC, el legislador estatal no solo está facultado, sino también obligado a proteger el demanio marítimo-terrestre a fin de asegurar tanto el mantenimiento de su integridad física y jurídica como su uso público y sus valores paisajísticos para servir a las funciones sociales que ampara el artículo $45 \mathrm{CE}$.

Una de las críticas que desde su aprobación ha recibido la LC ha sido que se vacía el contenido del título competencial en ordenación del litoral y que, al mismo tiempo, se condicionan las competencias urbanísticas de los municipios. En este sentido, MEILÁN GIL afirmaba que el título de dominio público se utilizaba "como ariete para incrementar las competencias estatales, en detrimento de las autonómicas y locales, al amparo de un expansivo régimen jurídico de protección y utilización del dominio público"10. En la misma línea, PERALES MADUEÑO afirmaba que "no parece tan claro que la protección de dominio público marítimo-terrestre permita invadir las competencias autonómicas en las áreas próximas al dominio mencionado"11.

Como sucedió con la aprobación de la LC en 1988, la LPUSL vuelve a cuestionar las competencias autonómicas en materia de ordenación del territorio, del litoral y de urbanismo en el ámbito costero y de los municipios en materia de autonomía local ${ }^{12}$. Aunque la LPUSL no modifica ninguno de los preceptos —artículos 110 a 115 LC que distribuyen las competencias entre las diferentes administraciones y que en su

\footnotetext{
${ }^{10}$ MEILÁN GIL, J. L., "Comunidades autónomas y dominio público marítimo-terrestre. El proyecto de Ley de costas”, Revista de Derecho Urbanístico y Medio Ambiente, núm. 108, 1988, p. 13 y ss.

${ }^{11}$ PERALES MADUEÑO, F., "Legislación urbanística y legislación sectorial. Un ejemplo: proyecto de la Ley de costas", Revista de Derecho Urbanístico y Medio Ambiente, núm. 108, 1988, p. 123 y ss.

${ }^{12}$ Sobre los problemas competenciales originados por la LC, véanse, entre otros, el Dictamen del Consell Consultiu de la Generalitat de Catalunya, núm. 148, sobre la adecuación constitucional y estatutaria de la Ley 22/1988, de 28 de julio, de Costas; MEILÁN GIL, J. L., "La Ley de costas y las competencias de las comunidades autónomas", Revista Gallega de Administración Pública, núm. 1, 1992; y BLASCO DÍAZ, J. L., "La distribución competencial en materia de costas", Revista d'estudis autonòmics i federals, núm. $10,2010$.
} 
preámbulo se afirma que "se respeta el complejo reparto competencial", ello no evita que el nuevo texto articulado no prevea mecanismos que planteen dudas razonables de constitucionalidad desde la perspectiva competencial $^{13}$, ya que se excede de las habilitaciones competenciales estatales ${ }^{14}$.

No obstante, el TC ya se ha pronunciado sobre esta controversia en diversas sentencias. Es el caso de la STC 233/2015, de 5 de noviembre, de la STC 6/2016, de 21 de enero, y de la STC 28/2016, de 18 de febrero.

A continuación analizamos, a la luz de la citada jurisprudencia del TC, la distribución competencial definida en la LC entre las tres administraciones territoriales.

\section{EL ALCANCE DE LAS COMPETENCIAS ADMINISTRATIVAS EN LA LEY DE COSTAS}

\section{Las competencias de la Administración del Estado}

La LC otorga a la Administración general del Estado un papel central en la gestión del dominio público marítimo-terrestre y en la planificación de un espacio que supera incluso este ${ }^{15}$.

Los artículos 110 a 113 LC $^{16}$ despliegan una exhaustiva lista de competencias, entre las cuales figuran no solo todas las competencias vinculadas con la gestión del dominio público marítimo-terrestre, sino también otras que condicionan las competencias autonómicas y locales.

\footnotetext{
${ }^{13}$ En este sentido, AGUIRRE I FONT, "L'impacte..." cit., p. 150.

${ }^{14}$ En este sentido, el Consell de Garanties Estatutàries de Cataluña, en el Dictamen 7/2013, de 11 de julio, sobre la reforma de la LC, concluye que se produce invasión de las competencias de la Generalitat en materia de ordenación del litoral, puertos y medio ambiente: "Sembla clar, a més, que la varietat de la costa i la diversitat dels tipus de les platges del litoral de l'Estat requereixen un tractament especific per part dels diferents instruments autonòmics d'ordenació litoral, sens perjudici que aquests respectin la categorització dels trams i les directrius que es puguin establir en la legislació bàsica per garantir la integritat física i l'accés públic d'aquesta part del domini" (FJ 3. ${ }^{\circ}$ ). También considera que la reforma operada vulnera el principio constitucional de autonomía municipal. En este sentido, afirma: " $A$ més, afegeix que l'article 119.2 LC podria infringir també l'autonomia local, en suspendre directament una decisió local, la qual cosa és una potestat que solament correspon als tribunals, llevat del supòsit excepcional d'atemptat greu a l'interès general d'Espanya previst a l'article 67 LBRL" (FJ 8. ${ }^{\circ}$ ).

${ }^{15}$ Vid. AGUIRRE I FONT, J. M., El régimen jurídico del litoral catalán. Especial referencia a la reforma de la Ley de Costas operada por la Ley 2/2013 y al nuevo Reglamento General de Costas aprobado por el Real Decreto 876/2014, Atelier, Barcelona, 2014, p. 71.

${ }^{16}$ Asimismo, los artículos 220 a 223 del RGC.
} 
Así, el artículo 110 LC otorga al Estado todas las competencias en el espacio de dominio público marítimo-terrestre, desde su delimitación hasta su tutela, sin tener en cuenta, como pone de manifiesto AGUIRRE I FONT, las competencias que comunidades autónomas con litoral como Cataluña habían asumido sobre la gestión de las playas ${ }^{17}$. De este modo, corresponde a la Administración general del Estado: “a) El deslinde de los bienes de dominio público marítimo-terrestre, así como su afectación y desafectación, y la adquisición y expropiación de terrenos para su incorporación a dicho dominio; $[\ldots]$ c) La tutela y policía del dominio público marítimo-terrestre y de sus servidumbres, así como la vigilancia del cumplimiento de las condiciones con arreglo a las cuales hayan sido otorgadas las concesiones y autorizaciones correspondientes".

Pero esta lista de competencias se complementa con otras que en algunos casos superan el ámbito estricto del dominio público marítimo-terrestre: “d) El ejercicio de los derechos de tanteo y retracto en las transmisiones de los yacimientos de áridos y, en su caso, la expropiación de los mismos; e) La realización de mediciones y aforos, estudios de hidráulica marítima e información sobre el clima marítimo; f) La aprobación de las normas elaboradas conforme a lo establecido en los artículos 22 y 34 de la presente Ley; g) Las obras y actuaciones de interés general o las que afecten a más de una Comunidad Autónoma; h) La autorización de vertidos, salvo los industriales y contaminantes desde tierra al mar; i) La elaboración y aprobación de las disposiciones sobre vertidos, seguridad humana en lugares de baño y salvamento marítimo; j) La iluminación de costas y señales marítimas; k) La prestación de toda clase de servicios técnicos relacionados con el ejercicio de las competencias anteriores y el asesoramiento a las Comunidades Autónomas, Corporaciones Locales y demás entidades públicas o privadas y a los particulares que lo soliciten; 1) La ejecución de los acuerdos y convenios internacionales en las materias de su competencia $\mathrm{y}$, en su caso, la coordinación e inspección de su cumplimiento por las Comunidades Autónomas, pudiendo adoptar, si procede, las medidas adecuadas para su observancia; m) La implantación de un Banco de Datos Oceanográfico que sirva para definir las condiciones de clima marítimo en la costa española, para lo cual las distintas Administraciones Públicas deberán suministrar la información que se les recabe. Reglamentariamente, se determinará el procedimiento de acceso a la información, que estará a disposición de quien la solicite".

\footnotetext{
${ }^{17}$ AGUIRRE I FONT, El régimen ... cit., p. 72.
} 
No obstante, la STC 149/1991, de 4 de julio, valida esta distribución competencial, si bien con algunos matices, ya que declara inconstitucional que las autorizaciones en la servidumbre de protección o para los vertidos de tierra a mar sean otorgados por el Estado, y condiciona la interpretación de otras competencias.

También cabe destacar la delimitación de lo que son las obras de interés general, que, de acuerdo con el artículo $111 \mathrm{LC}$, son competencia del Estado. Pero en el precepto citado no solo se realiza una descripción del concepto, sino que, como manifiesta AGUIRRE I FONT, las obras no están condicionadas ni a licencia municipal ni tampoco al planeamiento urbanístico o territorial, que en última instancia se tendrá que adaptar si así lo acuerda el Consejo de Ministros ${ }^{18}$.

Todo ello comporta que la Administración general del Estado tenga un amplio margen para la gestión del dominio público, pero también para condicionar las competencias de las otras administraciones ${ }^{19}$.

\section{Las competencias de las comunidades autónomas}

El ámbito competencial de las comunidades autónomas se prevé en el artículo 114 LC y en el artículo 224 RGC. Este es definido, a diferencia de las competencias de la Administración del Estado, de manera genérica y sin ninguna concreción.

Pero este ámbito competencial, con la reforma de la LC operada por la Ley 53/2002, de 30 de diciembre, de Medidas Fiscales, Administrativas y del Orden Social, quedó restringido "exclusivamente al ámbito terrestre del dominio público marítimo-terrestre, sin comprender el mar territorial y las aguas interiores" ${ }^{20}$. No obstante, el citado párrafo fue declarado inconstitucional por la STC 162/2012, de 30 de septiembre, que señalaba la "inconstitucionalidad de carácter formal" del citado precepto en la medida en que esta consideración trae causa de la invalidez del tipo normativo utilizado, dado que el legislador estatal no puede, sin una previsión constitucional o estatutaria específica, llevar a cabo "una interpretación conceptual y abstracta del sistema de distribución de competencias con el objetivo de delimitar las atribuciones de las Comunidades

\footnotetext{
${ }^{18}$ AGUIRRE I FONT, El régimen... cit., p. 73.

${ }^{19}$ Ibídem.

${ }^{20}$ Artículo 114.2 LC.
} 
Autónomas"21.

Así pues, solo excepcionalmente las comunidades autónomas pueden llegar a ejercer sobre el mar competencias autonómicas, siempre que exista un reconocimiento competencial explícito y cuando resulte imprescindible para el ejercicio de la competencia de la que son titulares, como el TC ha reafirmado en las sentencias 8/2013, de 17 de enero, y 99/2013, de 23 de abrill $^{22}$.

De este modo, las comunidades autónomas vieron como la LC las excluía de cualquier intervención en el dominio público marítimo-terrestre y, a la vez, afectaba de manera sustancial a otros títulos competenciales vinculados a este como el urbanismo o la ordenación del territorio. Pero la misma línea sigue la LPUSL, lo que, como ya se ha puesto de manifiesto, suscita dudas de constitucionalidad desde la perspectiva competencial.

\section{Las competencias de los municipios sobre su litoral}

El reconocimiento de las competencias municipales sobre el dominio público marítimoterrestre planteó inicialmente el problema de determinar si los espacios costeros formaban parte o no del término municipal. La jurisprudencia del TC ha reconocido que los puertos y la zona marítimo-terrestre forman parte del término municipal donde están ubicados "basándose en que legalmente todo el territorio nacional se divide en términos municipales de forma que no pueden quedar espacios territoriales excluidos de ellos" 23 . Existen, por lo tanto, competencias municipales sobre el dominio público marítimoterrestre.

La LC incluye en el artículo 115 un listado de las competencias de los municipios en esta materia. Pero este precepto no plantea una atribución directa de competencias, sino que remite a la legislación autonómica.

\footnotetext{
${ }^{21}$ Vid. GARCÍA PÉREZ, M. y SANZ LARRUGA, F.J., "La distribución de competencias en el medio marino", Arana García, E. y Sanz Larruga, F. J. (dirs.), La ordenación jurídica del medio marino en España. Estudios sobre la Ley 41/2010, de protección del medio marino, Thomson Reuters, Cizur Menor, 2012, pp. 299-300.

${ }^{22}$ En este sentido, AGUIRRE I FONT, El régimen ... cit., p. 74 y ss.

${ }^{23}$ STC 77/1984, de 3 de julio. Sobre esta cuestión, vid., entre otros, CALERO RODRÍGUEZ, J. R., Régimen Jurídico de las Costas Españolas, Aranzadi, Pamplona, 1995, pp. 125-127; y SÁINZ MORENO, F., "Término municipal y dominio marítimo", Revista de Administración Pública, núm. 112, 1987.
} 
No obstante, en el citado precepto se atribuye a los entes locales la competencia para informar sobre los deslindes o solicitudes de ocupación y aprovechamiento del dominio público, pero se trata en ambos casos de un informe no vinculante que en ningún caso tiene un carácter decisorio. Además, la LC atribuye dos competencias concretas de gestión del dominio público: “c) Explotar, en su caso, los servicios de temporada que puedan establecerse en las playas por cualquiera de las formas de gestión directa o indirecta previstas en la legislación de Régimen Local; d) Mantener las playas y lugares públicos de baño en las debidas condiciones de limpieza, higiene y salubridad, así como vigilar la observancia de las normas e instrucciones dictadas por la Administración del Estado sobre salvamento y seguridad de las vidas humanas".

En este caso la LC otorga a la Administración local un papel secundario ${ }^{24}$, planteamiento que ha sido objeto de crítica por parte de la doctrina al considerar que el legislador ha dejado perder la oportunidad de situar a la Administración local en el centro de la gestión, por ser una materia que afecta claramente a su círculo de intereses, como sucede en otros países de nuestro entorno ${ }^{25}$.

En cuanto a las dos competencias concretas de gestión del dominio público, estas están conectadas con el artículo 25 de la Ley 7/1985, de 2 de abril, reguladora de las Bases del Régimen Local $^{26}$ (LRBRL), donde se reconoce como competencia municipal la

\footnotetext{
${ }^{24}$ AGUIRRE I FONT, El régimen ... cit., p. 75.

${ }^{25}$ En este sentido, BELADÍEZ ROJO entiende que "la nueva Ley de Costas hubiera debido sacar a los municipios de una posición secundaria para situarlos en una más activa que permita una mejor protección del dominio público". Vid. BELADÍEZ ROJO, M., "Problemas competenciales sobre la zona marítimoterrestre y las playas", Martín-Retortillo Baquer, S. (coord.), Estudios sobre la Constitución Española. Homenaje al profesor Eduardo García de Enterría, vol. IV, Civitas, Madrid, 1991, p. 3704. En la misma línea, CALERO RODRÍGUEZ apunta que "es evidente que no lo ha hecho y que habrán de ser las leyes de las Comunidades Autónomas las que establezcan los términos concretos de estas competencias". Asimismo, este autor considera, "pese al tenor literal del primer inciso del art. 115, que esas competencias las ostentan ya los municipios sin esperar a que una ley autonómica les señale los términos precisos para su ejercicio". Y ello debería ser así tanto porque se refieren a cuestiones que afectan claramente a los intereses municipales cuanto porque no hay que olvidar que "se trata de competencias que la LBRL, en su art. 25, establece que han de ser atribuidas a los municipios, atribución que deberá ser realizada por la legislación del Estado, por ser a quien constitucionalmente le corresponde la competencia sobre estos bienes". CALERO RODRÍGUEZ, J. R., Régimen jurídico de las costas españolas, Aranzadi, Pamplona, 1995, pp. 125-134.

${ }^{26}$ Modificada por la Ley $27 / 2013$, de 27 de diciembre, de racionalización y sostenibilidad de la Administración Local, la cual tiene por objeto realizar una revisión completa del régimen jurídico aplicable a las entidades locales a través de la modificación de numerosos preceptos y disposiciones y de la introducción de otros nuevos de la LBRL y del texto refundido de la Ley reguladora de las Haciendas Locales, aprobado mediante el Real Decreto Legislativo 2/2004, de 5 de marzo. Vid., entre otros, MUÑOZ MACHADO, S., "Reflexiones sobre la pretendida reforma del régimen local", Diario de Derecho Municipal, 10 de junio de 2013; VELASCO CABALLERO, F., "Nuevo régimen de competencias municipales en el Anteproyecto de Racionalización y sostenibilidad de la Administración Local", Anuario de Derecho Municipal, núm. 6, pp. 23-60; ZAFRA VÍCTOR, M., "Reordenación de las
} 
protección del medio ambiente urbano, las actividades e instalaciones vinculadas a la ocupación del tiempo libre y la promoción de la actividad turística de interés y ámbito local $^{27}$. Sin embargo, a pesar de este reconocimiento de la protección del medio ambiente urbano y las demás materias citadas como competencia propia de los municipios, la LBRL no atribuye directamente competencias a los municipios, sino que será la legislación sectorial la que deberá concretar las competencias municipales en este ámbito ${ }^{28}$.

En relación con la explotación de los servicios de temporada, el artículo 54 LC permite que estos sean gestionados por titulares de concesiones de creación, regeneración o

competencias municipales, entre la eficacia y democracia”, Forcadell Esteller, X. y Sabaté Vidal, J. M. (coords.), La reforma local. Reptes $i$ oportunitats davant dels projectes de reforma del règim local impulsats pel govern estatal i el govern de la Generalitat, Diputación de Barcelona, 2013, pp. 46-60; FONT I LLOVET, T. y GALÁN GALÁN, A., "Racionalización y sostenibilidad de la Administración local: ¿es esta la reforma?", Anuario del Gobierno Local 2012, Fundación Democracia y Gobierno Local, Instituto de Derecho Público, Barcelona, 2013; ARENILlA SÁEZ, M., "El nuevo sistema de competencias locales", Santamaría Pastor, J. A. (coord.), La reforma de 2013 del régimen local español, Fundación Democracia y Gobierno Local, Madrid, 2013, pp. 15-55; QUINTANA LÓPEZ, T. (dir.), La reforma del régimen local: comentario a la Ley 27/2013, de 27 de diciembre, de racionalización y sostenibilidad de la Administración Local, Tirant lo Blanch, Valencia, 2014; TOSCANO GIL, F., "E1 nuevo sistema de competencias municipales tras la Ley de racionalización y sostenibilidad de la administración local: competencias propias y competencias distintas de las propias y de las atribuidas por delegación", Revista española de derecho administrativo, núm. 165, 2014, pp. 285-320; y FUENTES I GASÓ, J. R., "Consecuencias de la Ley 27/2013, de Racionalización y Sostenibilidad de la Administración Local, en el régimen local de Cataluña", Revista Vasca de Administración Pública, núm. 101, enero-abril 2015, pp. 55-88.

${ }^{27}$ La reforma de la LBRL a través de la Ley 27/2013, de 27 de diciembre, de racionalización y sostenibilidad de la Administración Local (LRSAL), ha provocado una redefinición y reclasificación de las competencias municipales mediante la modificación de los artículos 7, 25, 26 y 27 de la LBRL y la supresión del artículo 28 con el objetivo de evitar los problemas de solapamientos competenciales entre administraciones. Como afirma VELASCO CABALLERO, el eje de la LRSAL está en el intento de reducir la actividad municipal como supuesta fuente del déficit financiero. Vid. VELASCO CABALLERO, "Nuevo régimen..." cit., p. 4. En relación con la reordenación del sistema de competencias locales, vid., entre otros, RODRÍGUEZ BEAS, M. y FUENTES I GASÓ, J. R., "La organización territorial del Estatuto de 2006 y el impacto de la Ley 27/2013, de racionalización y sostenibilidad de la Administración Local en la interiorización del régimen local de Cataluña", García Rubio, F. (dir.), Análisis de las repercusiones de la reforma local sobre la organización, competencias y servicios de las entidades locales, INAP, Madrid, 2015, pp. 534 y ss.; y ARENILLA SÁEZ, M., "El nuevo sistema de competencias locales", Santamaría Pastor, J. A. (coord.), La reforma de 2013 del régimen local español, Fundación Democracia y Gobierno Local, Madrid, 2013, pp. 33-34.

${ }^{28}$ Esto se deriva del propio artículo 25.2 LBRL, que prevé que los municipios ejercerán estas competencias "en los términos de la legislación del Estado y de las Comunidades Autónomas". En consecuencia, como afirma CASADO CASADO, el reconocimiento de estas competencias en la legislación de régimen local constituye "únicamente un primer escalón en la definición de las competencias locales y será necesaria su concreción de la mano del legislador sectorial. Las materias enumeradas en el artículo 25 no son en sí mismas un título competencial, sino un mandato dirigido al legislador, estatal y autonómico, para que determine, en este marco declarado de interés local, las competencias en que efectivamente se concretará [...]". Vid. CASADO CASADO, L., "Las competencias ambientales de las entidades locales: luces y sombras tras la Ley 27/2013, de 27 de diciembre, de racionalización y sostenibilidad de la Administración local", Revista Aranzadi de Derecho Ambiental, núm. 32, septiembre-diciembre 2015, p. 234. 
acondicionamiento de playas. Pero esta disposición, como afirma AGUIRRE I FONT, limita todavía más las competencias de los municipios e incluso es contradictoria con los intereses propios de los municipios y su ámbito de competencias definido por la $\mathrm{LRBRL}^{29}$.

Por lo tanto, la atribución competencial operada por la LC excluye en parte la gestión del dominio público marítimo-terrestre de las funciones de los municipios, lo que resulta contrario a la doctrina jurisprudencial citada anteriormente.

\subsection{La suspensión de actos y acuerdos adoptados por las entidades locales}

La LPUSL vuelve a incidir en la vieja idea de incrementar el control estatal de los ayuntamientos mediante la cláusula conocida como "antialgarróbicos"30.

El artículo 1.38 LPUSL introduce un nuevo apartado en el artículo 119 LC en virtud del cual, y en aplicación del procedimiento previsto en el artículo 67 LBRL, el delegado del Gobierno podrá suspender los actos y acuerdos adoptados por las entidades locales que, bien afecten a la integridad del dominio público marítimo-terrestre o de la servidumbre de protección, bien supongan una infracción manifiesta de lo dispuesto en el artículo 25 LC, que regula el régimen de las actividades prohibidas y permitidas en dicha zona de servidumbre ${ }^{31}$.

MENÉNDEZ REXACH considera que la atribución de esta facultad suscita dudas de constitucionalidad porque va más allá del artículo 67 LBRL. Además, especifica que la doctrina del TC que considera que "los controles administrativos de legalidad no afectan al núcleo esencial de la garantía institucional de la autonomía de las corporaciones locales" porque "mediante tales controles se pretende garantizar que el ejercicio por las corporaciones locales de sus competencias no vaya en detrimento de las

\footnotetext{
${ }^{29}$ Vid. AGUIRRE I FONT, El régimen ... cit., p. 76. Asimismo, CALERO RODRÍGUEZ, Régimen jurídico... cit., p. 126.

${ }^{30}$ Hace referencia al caso que tuvo lugar en la playa del Algarrobico, en el término municipal de Carboneras (Almería), donde el planeamiento municipal autorizó la construcción de un hotel sobre la servidumbre de protección. Véase la STC de 29 de marzo de 2012, en la que se confirma la anterior Sentencia de la Audiencia Nacional de 23 de febrero de 2008, por la cual se desestima el recurso presentado por el Ayuntamiento de Carboneras contra el deslinde del dominio público efectuado por la Orden del Ministerio de Medio Ambiente de 8 de noviembre de 2005.

${ }^{31}$ Sobre esta cuestión, el Consell de Garanties Estatutàries afirma lo siguiente: “[...] un supòsit tan excepcional com el que preveu l'article 67 no qüestiona el principi constitucional d'exclusivitat judicial per a la suspensió dels actes municipals, però la seva extensió a altres àmbits equivaldria a minvar la pròpia autonomia constitucional municipal'.
} 
del Estado o de las propias de las Comunidades Autónomas" (SSTC 213/1988, de 11 de noviembre, FJ 2..$^{\circ}$ y 159/2001, FJ 5..$^{\circ}$ ) no se puede aplicar para la zona de protección, "que es precisamente donde se plantea el problema práctico, habida cuenta de que en ella la Administración General del Estado no es competente para autorizar los usos, mientras que sí lo es en el dominio público y la zona de tránsito, de modo que en estas zonas la licencia municipal no será suficiente para legitimar la actuación" ${ }^{32}$.

Profundizando en la argumentación de la inconstitucionalidad del precepto, cabe recordar que en la ya citada STC 149/1991 el Tribunal anuló el artículo 118 LC, por el que el Estado se atribuía la facultad de coordinar la actividad de la Administración local de acuerdo con el artículo 59 LBRL, porque tal remisión, sin condiciones ni límites, atentaba contra la autonomía local.

Además, no debe olvidarse que en la LC ya existen mecanismos de control estatal como el del artículo 117 LC, que exige el informe de la Administración del Estado para aprobar el planeamiento municipal ${ }^{33}$. Pero también el artículo 119.1 LC faculta a cualquier administración territorial para impugnar acuerdos y solicitar la suspensión en el supuesto que infrinjan la LC.

Por lo tanto, consideramos que el nuevo apartado segundo del artículo 119 LC resulta inconstitucional por vulnerar el principio de autonomía local y que no se ajusta a los mecanismos de control de la Administración local ${ }^{34}$.

\footnotetext{
${ }^{32}$ En definitiva, MENÉNDEZ REXACH manifiesta que "es muy dudoso que esta facultad sirva para evitar situaciones como la de ese malhadado hotel, pues no hay que olvidar que fue construido con licencia municipal (no impugnada, salvo error, ni por la Administración General del Estado ni por la Junta de Andalucía). Su demolición va a costar una fortuna que pagaremos los ciudadanos. Con este precedente y otros muchos de mala administración (por activa o por pasiva), presuponer que los ayuntamientos van a atentar contra la integridad del DPMT y que el delegado del Gobierno será siempre su celoso guardián, es pensar en lo excusado, como diría Cervantes". Vid. MENÉNDEZ REXACH, A., "La nueva regulación de las costas: un giro hacia el dominio privado marítimo-terrestre", Carro Fernández-Valmayor, J. L., Ferreira Fernández, J. y Nogueira López, A. (coords.), La nueva regulación de las costas: actas del IX Congreso de la Asociación Española de Profesores de Derecho Administrativo, INAP, Madrid, 2014, pp. 51-53. Sin embargo, MORENO MOLINA se muestra favorable a la constitucionalidad del precepto por cuanto se remite al artículo $67 \mathrm{LBRL}$, pero reconoce que su "inconcreción y generalidad es sin duda su aspecto más débil”. Vid. MORENO MOLINA, A. M., "Suspensión gubernativa de actos y acuerdos adoptados por las entidades locales. Cláusula antialgarrobico", Pérez Gálvez, J. F. y Alemán Monterreal, A. (coords.), Costas y urbanismo: el litoral tras la Ley 2/2013, de protección y uso sostenible del litoral y de modificación de la Ley de Costas, La Ley-El Consultor, Madrid, 2013, p. 823.

${ }^{33}$ En este sentido, sobre el caso del Algarrobico cabe recordar que ha quedado acreditada ante el Tribunal Supremo la falta de control de la Administración general del Estado. Véase la STS de 29 de marzo de 2012.

${ }^{34}$ Vid. AGUIRRE I FONT, “L'impacte...” cit., p. 153.
} 
Esta cláusula ha sido objeto de los recursos de inconstitucionalidad promovidos por el Consejo de Gobierno de Andalucía y por el Gobierno de la Generalitat de Catalunya por considerar que este mecanismo incurre en dos vicios de inconstitucionalidad alternativos. Así, se alega la vulneración del principio de autonomía local porque la imposición de este control desfigura el modelo de autonomía local diseñado por la LBRL, la cual ha establecido el monopolio judicial del control de legalidad de los actos y acuerdos de los entes locales, admitiendo únicamente como excepción en su artículo 67.1 la suspensión gubernativa de los actos y acuerdos de los entes locales que atenten gravemente al interés del Estado, a cargo del delegado del Gobierno, quien deberá proceder a su posterior impugnación en el plazo de diez días desde la suspensión ante la jurisdicción contencioso-administrativa. En caso de no apreciarse, consideran que invade la competencia autonómica en materia de ordenación del territorio y urbanismo, y, más concretamente, la competencia sobre la protección de la legalidad urbanística, en la medida en que se atribuye a un órgano estatal el ejercicio de una competencia que pertenece a las autoridades autonómicas.

Ambas tachas de inconstitucionalidad han sido desestimadas, primero en la STC 6/2016 y más tarde en la STC 28/2016, que reitera la doctrina de la primera. En cuanto a la primera de ellas, siguiendo su doctrina sobre el significado del principio de autonomía local en su concreta proyección sobre tales controles (SSTC 4/1981, de 2 de febrero, y 154/2015, de 9 de julio, entre otras), concluye que "desde la perspectiva de la autonomía local constitucionalmente garantizada, el art. 119.2 LC cumple las antedichas exigencias al estar prevista la suspensión en norma con rango de ley, acotando su objeto con precisión suficiente e incidir claramente en intereses supralocales, como son los relativos a la protección y defensa de la integridad del dominio público marítimoterrestre de titularidad estatal"35.

$\mathrm{Y}$ en cuanto a la segunda, trasladando también su doctrina previa (entre otras, SSTC 214/1989, de 21 de diciembre; 149/1991, de 4 de julio; y 162/2012, de 20 de septiembre), concluye que resulta "constitucionalmente legitima la intervención de un órgano estatal a través de un mecanismo cautelar y extraordinario, cuando el acto local afectado por la medida de suspensión pueda comprometer la integridad del demanio, la preservación de sus características naturales o su libre utilización pública y gratuita, y que en última instancia queda sometido al control de la jurisdicción contencioso${ }^{35} \mathrm{FJ} 4 \mathrm{~d}$. 
administrativa. Estamos en definitiva ante una potestad, con la connotación de excepcionalidad que deriva del artículo 67 LBRL, que no cuestiona, sustituye o altera las competencias ejecutivas de las Comunidades Autónomas sobre el litoral, sino que responde, como las que ya fueron objeto de enjuiciamiento en la STC 149/1991, no tanto a la facultad como a la obligación estatal de impedir que la naturaleza de estos bienes y sus características sean destruidas o alteradas [STC 233/2015, FJ 2a), con cita de la STC 149/1991, FJ 1c]"36.

\section{LA DEMANIALIDAD: INSTRUMENTO ESENCIAL DE PROTECCIÓN DE LAS COSTAS}

La institución clave que garantiza la protección de las costas en España es el "dominio público" o "demanialización", que actúa como título de intervención del Estado para garantizar la defensa del interés general y la protección del medio ambiente.

La demanialización se configura como el mecanismo más adecuado para lograr aquella finalidad debido a las reglas exorbitantes de derecho público que conlleva, como la inalienabilidad, imprescriptibilidad e inembargabilidad, la necesidad de desafectación para su disposición o el resto de potestades públicas que se pueden ejecutar para su protección $^{37}$, y también por la obligación que recae en la Administración titular de dichos bienes de articular las normas de utilización y aprovechamiento que garanticen la protección de su integridad $^{38}$.

Se reconoce expresamente el mencionado dominio público en el artículo 132.2 CE, que declara bienes de dominio público estatal aquellos que determine la Ley y, en todo caso, la zona marítimo-terrestre, las playas, el mar territorial y los recursos naturales de la zona económica y la plataforma continental ${ }^{39}$. Este reconocimiento constitucional de los

\footnotetext{
${ }^{36}$ En la STC 28/2016, el FJ 5. ${ }^{\circ}$ reitera su posicionamiento.

${ }^{37}$ En los artículos 7 y ss. LC se recoge la aplicación al dominio público marítimo-terrestre de las potestades exorbitantes de la institución demanial. Parte de la doctrina considera estos preceptos innecesarios teniendo en cuenta que las líneas esenciales se recogen el artículo 132.1 CE. Vid., entre otros, GONZÁLEZ SALINAS, Régimen actual... cit., p. 399; y RODRÍGUEZ LÓPEZ, Comentarios a la LC... cit., p. 51.

${ }^{38}$ VILLANUEVA CUEVAS, A., PUNZÓN MORALES, J. y SÁNCHEZ RODRÍGUEZ, F., "La protección medioambiental de las costas", Ortega Álvarez, L. I., Alonso García, M. C. y De Vicente Martínez, R. (coord.), Tratado de derecho ambiental, Tirant lo Blanch, Valencia, 2013, p. 595.

${ }^{39}$ Como afirman estos autores, de este precepto constitucional conviene resaltar no solo la enumeración de bienes que se incluyen en el dominio público marítimo-terrestre, sino también la importancia de que estos sean dominio público estatal. Vid. VILLANUEVA CUEVAS, PUNZÓN MORALES y SÁNCHEZ
} 
bienes actúa como un límite indisponible para el legislador. La LC es la encargada de desarrollar este artículo $132 \mathrm{CE}$ en las costas del Estado español, convirtiendo la figura del dominio público marítimo-terrestre en el eje central sobre el que gravita el sistema de protección del litoral ${ }^{40}$.

Por lo tanto, se atribuyen al Estado facultades y obligaciones a fin de proteger el dominio público marítimo-terrestre. Pero no solo le corresponde definir los bienes que pertenecen al dominio público, sino que debe articular su régimen jurídico, ya que, como señaló el $\mathrm{TC}$, es una necesidad constitucional porque "el mandato del constituyente quedaría burlado si el legislador obrase de tal modo que, aun reteniendo físicamente en el dominio público del Estado la zona marítimo-terrestre, tolerase que su naturaleza y sus características fueran destruidas o alteradas" ${ }^{41}$.

Los artículos 3 a 5 LC amplían el ámbito concreto de la "declaración de demanialidad" efectuada por la $\mathrm{CE}$, determinando que pertenecen al dominio público estatal, además de los bienes a que se refiere el artículo $132.2 \mathrm{CE}^{42}$, los siguientes: las accesiones en la ribera del mar por depósito de materiales o por retirada del mar; los terrenos ganados al mar como consecuencia directa o indirecta de obras o desecados; los terrenos cuya superficie sea invadida por el mar por causas distintas a las previstas en el último

RODRÍGUEZ, “La protección...”, cit., p. 597. La STC 227/1988, de 29 de noviembre, resuelve las discrepancias sobre esta asignación constitucional atendiendo a la mayor protección que para aquellos bienes significa la titularidad estatal de estos, indicando que "no es casual, como lo demuestran los antecedentes parlamentarios, que la Constitución haya incorporado directamente al dominio público estatal en el art. 132.2 determinados tipos de bienes que, como la zona marítimo-terrestre, las playas, el mar territorial, etc., constituyen categorías o géneros enteros definidos por sus características físicas o naturales homogéneas" y "tratándose del demanio público es lógico que la potestad de demanializar se reserve al Estado en exclusiva y que los géneros que lo integran se incluyen, así mismo, como unidad indivisible en el dominio estatal [...]. En estos bienes subyacen prioritariamente otros fines constitucionalmente legítimos, vinculados en última instancia a la satisfacción de necesidades colectivas primarias, como por ejemplo, la que garantiza el art. 45 de la Constitución, o bien a la defensa y utilización racional de la 'riqueza del país', en cuanto subordinada al interés general (art. 128.1 de la Constitución)” (FJ 14. ${ }^{\circ}$ ).

${ }^{40}$ Sobre el dominio público marítimo-terrestre en la Constitución española, véase BLASCO DÍAZ, J. L., Régimen jurídico de las propiedades particulares en el litoral, Tirant lo Blanch, Valencia, 1999, p. 34 y ss.

${ }^{41}$ STC $149 / 1991$.

${ }^{42}$ Respecto a estos bienes recogidos en la misma CE, vid., entre otros, CALERO RODRÍGUEZ, J. R., Régimen jurídico de las costas españolas, Aranzadi, Pamplona, 1995; GONZÁLEZ SALINAS, J., Régimen jurídico actual de la propiedad en las costas, Civitas, Madrid, 2000; MEILÁN GIL, J. L., "El concepto de dominio público marítimo-terrestre en el Proyecto de LC", Revista española de derecho administrativo, núm. 59, 1988; MEILÁN GIL, J. L., "El dominio público natural y la legislación de costas", Revista de Administración Pública, núm. 139, enero-abril, 1996; MENÉNDEZ REXACH, A., "La configuración del dominio público marítimo-terrestre en la LC”, Estudios Territoriales, núm. 34, 1990; y RODRÍGUEZ LÓPEZ, P., Comentarios a la LC, Doctrina y Jurisprudencia, Dijusa, Madrid, 2003. 
párrafo del artículo 3.1 a) LC, y en todo caso tendrán esta consideración los terrenos inundados que sean navegables; los acantilados sensiblemente verticales hasta su coronación; los terrenos delimitados como dominio público que por cualquier causa hayan perdido sus características naturales de playa, acantilado o zona marítimoterrestre; los islotes en aguas interiores y mar territorial; los terrenos incorporados por los concesionarios para completar la superficie de su concesión; los terrenos colindantes con la ribera del mar que se adquieran para su incorporación al dominio público marítimo-terrestre; las obras e instalaciones construidas por el Estado en este dominio; las obras e instalaciones de iluminación de costas y señalización marítima construidas por el Estado y los terrenos afectados a ellas; y los puertos y las instalaciones portuarias de titularidad estatal, que se regularán por su legislación específica.

Como se puede comprobar, la LC realiza una extensión importante del dominio público que se afianza en el artículo 9.1 mediante la prohibición de construir y/o mantener enclaves privados en esta zona.

La declaración de dominio público de estos bienes tiene como finalidad la eliminación de la capacidad de disposición por los particulares sobre estos y la inclusión de una serie de medidas para protegerlos. El primer objetivo — la indisponibilidad - se consigue mediante su consideración como res extra commercium sustraídas del tráfico jurídicoprivado para su afectación a un uso público u otros fines de utilidad pública. De esta caracterización derivan las notas de inalienabilidad, imprescriptibilidad e inembargabilidad, así como la atribución de una serie de potestades a la Administración con el fin de proteger y garantizar el uso público de estos bienes: derecho-deber de investigación de la situación de los bienes que se presumen pertenecientes al dominio público, de recuperación posesoria y potestad de deslinde. El segundo objetivo se logra mediante el establecimiento de una serie de medidas para evitar su degradación como la regulación del régimen de usos, el sometimiento de determinados usos a autorización o concesión administrativa, el establecimiento de un régimen de limitaciones y servidumbres sobre las propiedades contiguas al dominio público, la regulación de los vertidos, etc. 


\section{La delimitación de los bienes que forman parte del dominio público marítimo- terrestre: la exclusión de determinados bienes de la ribera del mar}

Una de las reformas de la LPUSL con más consecuencias sobre el espacio protegido es la reducción de los bienes que forman parte de la ribera del mar, $\mathrm{y}$, por consiguiente, del dominio público marítimo-terrestre, a través de la exclusión singular de determinados espacios del régimen general de la $\mathrm{LC}^{43}$.

Con el objetivo de reducir el espacio protegido, la LPUSL utiliza diferentes técnicas para excluir los espacios del régimen general: se redefinen los bienes que forman parte de la ribera de mar; se excluyen determinados paseos marítimos del dominio público marítimo-terrestre; se excluyen núcleos de población del dominio público marítimoterrestre; se crean criterios de delimitación para la isla de Formentera; se excluyen del régimen general del dominio público marítimo-terrestre las urbanizaciones marítimoterrestres; y se reduce la servidumbre de protección ${ }^{44}$.

Pero estas técnicas no solo suponen una reducción del espacio protegido, sino que en la mayoría de casos se otorga el derecho a los propietarios originales del dominio público desafectado a reclamar la propiedad de los terrenos en el caso de que dispongan de título inscrito en el registro de la propiedad, de acuerdo con las disposiciones adicionales cuarta, quinta, sexta y séptima de la Ley ${ }^{45}$.

A continuación analizamos solo algunas de estas técnicas, ya que por cuestiones de espacio nos centramos exclusivamente en las principales consecuencias de la reforma a la luz de la jurisprudencia constitucional más reciente.

\footnotetext{
${ }^{43}$ Para un estudio más exhaustivo, vid. MARTíNEZ CORDERO, J. R., "Clasificación y definiciones", Pérez Gálvez, J. F., El nuevo derecho de costas, Bosch, Barcelona, 2014, pp. 47-93; y FERNÁNDEZ DE TROCÓNIZ, F., "El nuevo concepto de dominio público y sus consecuencias legales tras la reforma de la Ley de Costas", Torres-Fernández Nieto, J. J., Fernández de Trocóniz, F. C., Olano Espinosa, C., Menéndez Menéndez, A., González de Olano, G., Cancer Minchot, P. y Risquete, J. L., Comentario a la Ley 2/2013, de 29 de mayo, de Protección y Uso Sostenible del Litoral y de Modificación de la Ley 22/1988, de Costas, Thomson Reuters Aranzadi, Cizur Menor, 2014, pp. 87-132.

${ }^{44}$ Sobre estas cuestiones, véanse, entre otros, NOGUERA DE LA MUELA, B. y AGUIRRE I FONT, J. M., "Costas y urbanismo: de la Ley de costas al Proyecto de la ley de protección y uso sostenible del litoral y de modificación de la Ley 22/1988, de 28 de julio, de costas", López Ramón, F. y Escartín Escudé, V. (coords.), Bienes públicos, urbanismo y medio ambiente, Marcial Pons, Madrid, 2013; y NUÑEZ LOZANO, M. C., La reforma de la Ley de Costas, Civitas Thomson Reuters, Navarra, 2013.

${ }^{45}$ AGUIRRE I FONT, "L'impacte..." cit., p. 144.
} 


\subsection{La zona marítimo-terrestre}

La "zona marítimo-terrestre" se configura en el artículo 3 LC como la parte inundable de la ribera del mar ${ }^{46}$. Pero como se puede observar en ese precepto, se utilizan dos criterios para delimitar sus dimensiones: a) hasta donde alcancen las olas de los mayores temporales conocidos; y b), de forma secundaria, el de la línea que alcance la pleamar máxima viva equinoccial ${ }^{47}$.

El problema de esto es determinar qué se entiende por "mayores temporales conocidos", para lo cual se hace necesario acudir al RGC, en cuyo artículo 4 se especifica que "para fijar el límite hasta donde alcanzan las olas en los mayores temporales conocidos, se considerarán las variaciones del nivel del mar debidas a las mareas y el oleaje. Dicho límite será el alcanzado al menos en 5 ocasiones en un periodo de 5 años, salvo en aquellos casos excepcionales en que la mejor evidencia científica existente demuestre la necesidad de utilizar otro criterio. Para calcular el alcance de un temporal se utilizarán las máximas olas registradas con boyas o satélites o calculadas a través de datos oceanográficos o meteorológicos". MENÉNDEZ REXACH ya justificó esta necesidad de utilizar las referencias comprobadas de que se disponga en relación con el anterior Reglamento, al decir que "es razonable la pretensión del legislador de considerar zona marítimo-terrestre toda la franja costera susceptible de invasión por el mar, por haberlo sido ya en alguna ocasión de que se tenga constancia" ${ }^{\text {"48 }}$.

La LPUSL modifica la LC en lo que concierne a la delimitación de la ribera del mar. Por lo que respecta a la zona marítimo-terrestre, la modificación introducida en el primer párrafo del artículo 3.1 a) LC por el artículo 1.2 LPUSL consiste, únicamente, en la especificación de que el límite constituido por el alcance de las olas en los mayores temporales conocidos vendrá dado por los criterios técnicos que se establezcan reglamentariamente. Hasta entonces, el artículo 4 a) RGC había dispuesto que "para

\footnotetext{
${ }^{46}$ Sobre nuevas fórmulas de delimitación de la "zona marítimo-terrestre", vid., in totum, la tesis doctoral inédita de MONTOYA FONT, F. J., Propuesta de metodología para la determinación del límite interior del dominio público marítimo-terrestre en algunos supuestos, Universitat Rovira i Virgili, Tarragona, 2013.

${ }^{47}$ Como explican VILLANUEVA CUEVAS, PUNZÓN MORALES y SÁNCHEZ RODRÍGUEZ, la razón de la existencia de este doble criterio de delimitación "se debe a que las mareas son escasamente perceptibles en el Mediterráneo, lo que ha conllevado que en nuestra legislación histórica en las costas bañadas por aquél se utilizará el criterio de los temporales y, en el resto de costas españolas, el criterio de las mareas". Vid. VILLANUEVA CUEVAS, PUNZÓN MORALES y SÁNCHEZ RODRÍGUEZ, "La protección..." cit., p. 601.
}

${ }^{48}$ MENÉNDEZ REXACH, A., "La configuración del dominio público marítimo-terrestre en la LC", Estudios Territoriales, núm. 34, septiembre-diciembre, 1990, p. 12. 
fijar el límite hasta donde alcanzan las olas en los mayores temporales conocidos se utilizaran las referencias comprobadas de que se dispongan". Pero, tras la reforma operada, el Reglamento viene obligado a detallar la metodología o el procedimiento técnico que se ha de seguir para dilucidar con certeza hasta dónde alcanzan las olas de un temporal.

Esta cuestión ha sido tachada de inconstitucionalidad por vulnerar el artículo $132.2 \mathrm{CE}$ ya que la nueva redacción del apartado a) del artículo 3.1 LC convierte la categoría de zona marítimo-terrestre en algo coyuntural y variable sujeto a unos criterios técnicos que no se fijan en la Ley como exige la Constitución, sino que quedan indefinidos al remitirse a un reglamento posterior ${ }^{49}$.

No obstante, la STC 233/2015 afirma que la reforma del citado precepto no contraviene su doctrina consolidada respecto a que "la reserva de ley no impide que las leyes contengan remisiones a normas reglamentarias, pero sí que tales remisiones hagan posible una regulación independiente y no claramente subordinada a la Ley [...]. Ahora bien, las habilitaciones a la potestad reglamentaria deben, según nuestra doctrina, restringir el ejercicio de dicha potestad a un complemento de la regulación legal que sea indispensable por motivos técnicos o para optimizar el cumplimiento de las finalidades propuestas por la Constitución o por la propia ley, de modo que no se llegue a una total abdicación por parte del legislador de su facultad para establecer reglas limitativas, transfiriendo esa facultad al titular de la potestad reglamentaria, sin fijar ni siquiera cuáles son los fines u objetivos que la reglamentación ha de perseguir" ${ }^{\circ 0}$.

De este modo, apoyándose en la citada doctrina, el TC afirma que la reforma no altera en modo alguno el criterio legal sustantivo anterior a la reforma "que sirve para fijar el límite interior de la zona marítimo-terrestre por referencia al alcance de las olas en los mayores temporales conocidos. Se limita a remitir la concreción de este criterio decisor, netamente empírico y, por definición, variable tanto en el espacio como en el tiempo, a una normativa que responda al conocimiento técnico, en constante evolución. Con ello no hace sino incrementar las garantías de rigor, objetividad y homogeneidad en la

\footnotetext{
${ }^{49}$ En este sentido se fundamenta el motivo de impugnación de la LPUSL en el recurso de inconstitucionalidad interpuesto por el Consejo de Gobierno de Andalucía.

${ }^{50}$ STC 83/1984, de 24 de julio, FJ 4. ${ }^{\text {.; }}$ STC 1/2003, de 16 de enero, FJ 3. ${ }^{\text {. }}$, STC 18/2011, de 3 de marzo, FJ 9. .
} 
práctica de los deslindes" ${ }^{, 51}$. Por lo tanto, la modificación se limita a incorporar una precisión que encaja sin ninguna dificultad en el ámbito admisible de la colaboración reglamentaria ${ }^{52}$.

Otra modificación importante que afecta a la zona marítimo-terrestre es la matización de que esta la integran solo las partes de los terrenos bajos que se inundan. Este supuesto es problemático, ya que si los terrenos se inundan es, precisamente, porque son bajos $^{53}$, motivo por el cual no habría "partes" de terrenos bajos que no se inundan ${ }^{54}$. No obstante, como pone de manifiesto NÚÑEZ LOZANO, sí puede suceder que en un entorno de terrenos bajos existan porciones que registren de forma natural una mayor cota, en cuyo caso no serían propiamente terrenos bajos; o también puede ocurrir que terrenos originariamente bajos hayan sido modificados por la acción del hombre, de manera que se haya elevado artificialmente su cota o que, manteniendo su conformación como terrenos bajos, su inundación natural haya sido impedida de manera $\operatorname{artificial}^{55}$.

Por otro lado, la reforma incluye un nuevo párrafo en el artículo 3.1 a) LC que dispone que, "no obstante, no pasarán a formar parte del dominio público marítimo-terrestre aquellos terrenos que sean inundados artificial y controladamente, como consecuencia de obras o instalaciones realizadas al efecto, siempre que antes de la inundación no fueran de dominio público". Así, si para la LC eran demaniales los terrenos invadidos por el mar que pasen a formar parte de su lecho por cualquier causa, ahora quedan excluidos los que reúnan los requisitos establecidos en el artículo 3.1 a), salvo que fueran navegables. La especificación final — “siempre que antes de la inundación no fueran de dominio público" - resulta importante porque descarta la posibilidad de entender que se refiere a terrenos naturalmente inundables que se inundan de modo artificial y controlado por la acción humana, como es el caso de las salinas ${ }^{56}$.

\footnotetext{
${ }^{51}$ STC de 5 de noviembre de 2015, FJ 3a.

${ }^{52}$ En el mismo sentido se pronuncia la reciente STC 6/2016, de 21 de enero, FJ 3. ${ }^{\circ}$.

${ }^{53}$ GARCÍA PÉREZ, M., "La reforma de la Ley de Costas: un lobo con piel de cordero", El Cronista del Estado Social y Democrático de Derecho, núm. 31, 2012, p. 65.

${ }^{54}$ NÚÑEZ LOZANO, M. C., La reforma de la Ley de Costas de 2013, Tirant lo Blanch, Valencia, 2013, p. 29.

${ }^{55}$ La jurisprudencia ha declarado de forma constante el carácter demanial de los terrenos. Vid. NÚÑEZ LOZANO, La reforma ... cit., p. 29.

${ }^{56}$ En este sentido, ibídem, p. 31.
} 
De este modo, el precepto citado hace referencia a terrenos que no son naturalmente inundables y que por ello nunca han sido deslindados como de dominio público. En este aspecto, la reforma se ha limitado a incluir un precepto aclaratorio, ya que es conforme con la proclamación de la demanialidad que contempla el párrafo segundo del artículo 3.1 a) $\mathrm{LC}^{57}$.

No obstante, el nuevo párrafo supone una reducción de la franja demanial, ya que no especifica que los terrenos tengan una cota superior a la de mayor pleamar. Así, los terrenos con cota inferior a la pleamar que no se inundan debido a causas naturales pero que son inundados de modo artificial no se demanializan, salvo que sean navegables conforme al artículo $4.3 \mathrm{LC}^{58}$.

Finalmente, el nuevo apartado cuarto del artículo 3 incluye las definiciones de "albufera" ("cuerpos de aguas costeras que quedan físicamente separados del océano, en mayor o menos extensión por una franja de tierra"), "estero" (“caños en una marisma”), "marisma" ("terreno muy llano y bajo que se inunda periódicamente como consecuencia del flujo y reflujo de las mareas o de la filtración del agua del mar") y "marjal" (“terreno bajo cubierto por un manto de agua que da soporte a abundante vegetación”).

\subsection{Las playas}

Las "playas", según la definición recogida en el apartado b) del artículo 3.1 LC, son aquellas zonas no inundables en terrenos de cota superior a la zona marítimo-terrestre y que se identifican por poseer unas características físicas determinadas ${ }^{59}$ : zonas de depósito de materiales sueltos, tales como arenas, gravas y guijarros, incluyendo escarpes, bermas y dunas; estas últimas se incluirán hasta el límite que resulte necesario para garantizar la estabilidad de la playa y la defensa de la costa. Constituyen lo que MENÉNDEZ REXACH denomina "playa seca” por contraposición a la zona marítimo-

\footnotetext{
${ }^{57}$ Sobre esta modificación se ha pronunciado el TC, manifestando que la reforma legal no infringe el artículo 132.2 CE, cuyo inciso final - "siempre que antes de la inundación no fueran de dominio público"- acota de forma significativa la reforma y salva su constitucionalidad porque "supone que no quedan afectados por la exclusión los terrenos naturalmente inundables, que son en todo caso zona marítimo-terrestre, de dominio público por imperativo constitucional". Vid. STC 233/2015, de 5 de noviembre de 2015, FJ 3 b.

${ }^{58}$ Como afirma AGUIRRE I FONT, esto excluye de la ribera del mar, por ejemplo, algunas explotaciones salinas e instalaciones de acuicultura que hasta la reforma formaban parte de ella, de acuerdo con el criterio jurisprudencial del Tribunal Supremo. Vid. AGUIRRE I FONT, "L'impacte... cit., p. 145. Véase también, STS de 11 de noviembre de 2010.

${ }^{59}$ MENÉNDEZ REXACH, “La configuración...” cit., p. 14.
} 
terrestre, que sería la "playa húmeda"60. De este modo, las playas estarían localizadas a partir del límite tierra adentro de la zona marítimo-terrestre ${ }^{61}$.

La LPUSL modificó el artículo 3.1 b) LC para especificar que las dunas se incluyen en el demanio hasta el límite que resulte necesario para garantizar la estabilidad de la playa y la defensa de la costa ${ }^{62}$. No se trata de una modificación sin importancia, ya que hasta ahora la ribera del mar incorporaba todas las dunas con independencia de su origen o de si eran o no necesarias para la estabilidad de la playa, como lo había reconocido la jurisprudencia ${ }^{63}$.

Esta modificación ha sido objeto de impugnación ante el TC por parte del Gobierno de la Generalitat de Catalunya y el Consejo de Gobierno de Andalucía ${ }^{64}$. Los recurrentes alegaban que se limita indebidamente el ámbito del dominio público al excluir espacios que forman parte de un único ecosistema, pues solo quedarán protegidos per relationem con otros elementos del litoral, con lo que se infringe el principio de seguridad jurídica de los artículos 9.3 y 132.2 CE. Consideran que la nueva redacción del precepto en cuestión vulnera el artículo $132 \mathrm{CE}$ por cuanto rebaja el régimen de protección de los bienes de dominio público marítimo-terrestre al que el legislador estatal se encuentra vinculado positivamente. Con la reforma operada por la LPUSL se permite la existencia de enclaves privados. Además, la exclusión de las dunas artificiales y muertas carece de justificación, incluso si se limita su consideración al concepto de duna viva, remitiéndose para su acotación no ya a criterios reglamentarios sino incluso a actos administrativos posteriores que se realicen con ocasión de la práctica del deslinde. De este modo, el legislador no tiene en cuenta el valor instrumental de las dunas para la protección del ecosistema. Esto resulta incompatible con el artículo $45 \mathrm{CE}$ por cuanto el legislador omite su obligación de proteger el demanio público marítimo-terrestre al no mantener su integridad física y jurídica, su uso público y sus valores paisajísticos.

El TC considera, extrapolando a este caso lo manifestado en la STC 149/1991 a propósito de la delimitación de la zona marítimo-terrestre, que el hecho de que la nueva

\footnotetext{
${ }^{60}$ Ibídem.

${ }^{61}$ Este dato es importante porque es a partir del límite interior de las playas desde donde se comienzan a medir las limitaciones a la propiedad sobre los terrenos particulares colindantes.

${ }^{62}$ Esta precisión ya se encontraba en el artículo 4 d) RGC por referencia a las dunas fijadas por la vegetación.

${ }^{63}$ Vid. AGUIRRE I FONT, “L’impacte...” cit., p. 145.

${ }^{64}$ Interpusieron los recursos de inconstitucionalidad números 5012-2013 y 4906-2013, respectivamente.
} 
Ley utilice para su delimitación "una definición distinta de un concepto ya utilizado por leyes anteriores sobre la materia, no es, ciertamente, razón alguna que abone su inconstitucionalidad. Una cosa es que las instituciones públicas o los institutos de Derecho privado constitucionalmente garantizados no pueden ser modificados en términos que afecten a su contenido esencial, de manera que, aun conservándose la antigua denominación, ésta venga a designar un contenido en el que la conciencia social no reconoce ya la institución garantizada y otra bien distinta que el legislador no pueda modificar las definiciones o los criterios definitorios de realidades naturales, no jurídicas, a las que la Constitución alude" ${ }^{\text {" }}$. Del mismo modo, el TC desestima esta tacha de inconstitucionalidad en la reciente Sentencia 6/2016 afirmando que "no es posible apreciar que la nueva regulación de las dunas suponga la incorporación de criterios de delimitación del dominio público natural que puedan poner en riesgo su integridad" 66 .

Por otro lado, la reforma incluye la definición formal de "dunas", que son depósitos sedimentarios constituidos por montículos de arena, tengan o no vegetación, que se alimenten de la arena transportada por la acción del mar, del viento marino o por otras causas (art. 3.4 LC). Como afirma NÚÑEZ LOZANO, la virtualidad de esta reforma es la exclusión del demanio de las "dunas muertas", la cual ya la habría operado el antiguo artículo 4 d) RGC respecto de las fijadas por la vegetación, excluyendo las que no fueran necesarias para garantizar la estabilidad de la playa y la defensa de la costa, y, aún más, con la referencia a las cadenas de dunas que estén en desarrollo, desplazamiento o evolución ${ }^{67}$. Estas últimas se consideran, en cambio, “dunas vivas", y las dunas con vegetación se consideran vivas en tanto en cuanto dicha vegetación no las haya fijado plenamente, de manera que aún sigan siendo necesarias para garantizar la estabilidad de la playa y la defensa de la costa.

En este sentido, el propio TC constata que esta reforma es una innovación relativa, porque ya el artículo 4 d) RGC, tras incluir en la delimitación de la playa las cadenas de dunas que estén en desarrollo, desplazamiento o evolución debida a la acción del mar o del viento marino, modulaba la inclusión de las restantes dunas limitándose a las "fijadas por vegetación hasta el límite que resulte necesario para garantizar la

\footnotetext{
${ }^{65} \mathrm{FJ} 3 \mathrm{c}$.

${ }^{66} \mathrm{FJ} 3 .^{\circ}$.

${ }^{67}$ NÚÑEZ LOZANO, La reforma... cit., p. 34.
} 


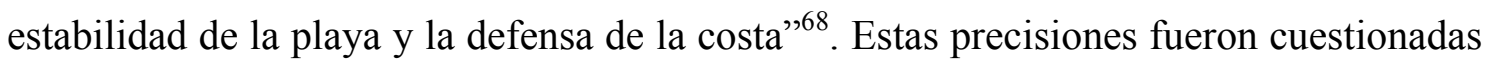
en su momento por la doctrina ${ }^{69}$. Sin embargo, como precisa NÚÑEZ LOZANO, no se reparó en que la inclusión de las dunas con las características señaladas podía significar la exclusión de las dunas muertas ${ }^{70}$.

Pero es ahora la propia Ley la que incluye las dunas hasta el límite que resulte necesario para garantizar la estabilidad de la playa y la defensa de la costa, motivo por el cual puede sostenerse que se excluyen del ámbito de la playa las dunas muertas.

Por lo tanto, la elevación de rango del criterio expresado en el anterior RGC, según el TC, “admite la misma interpretación, que por lo demás aparece confirmada en su actual desarrollo reglamentario"

Finalmente, el nuevo apartado 4 del artículo 3 LC incluye, junto a la definición de duna ya examinada, las de "berma" y "escarpe". La berma es "la parte casi horizontal de la playa, interior al escarpe o talud de fuerte pendiente causada por el oleaje", y el escarpe es el "escalón vertical en la playa formado por la erosión de la berma". La definición de berma coincide con la que ya proporcionaba el artículo 4 c) RGC, mientras que la de escarpe podía deducirse de la de berma, aunque en esta se expresa la causa concreta del escarpe, el oleaje, y en la de escarpe que se incorpora a la LC simplemente se menciona la erosión de la berma.

\subsection{Los terrenos cuya superficie sea invadida por el mar}

El artículo 4.3 LC indicaba que "pertenecen asimismo al dominio público marítimoterrestre estatal [...] los terrenos invadidos por el mar que pasen a formar parte de su lecho por cualquier causa". Pero tras la reforma operada por la LPUSL, el citado precepto ha quedado redactado así: "[...] pertenecen asimismo al dominio público marítimo-terrestre estatal [...] los terrenos cuya superficie sea invadida por el mar

\footnotetext{
${ }^{68}$ Sobre esta previsión reglamentaria se ha pronunciado el Tribunal Supremo advirtiendo que, para excluir una duna del dominio público estatal, se precisa una prueba específica y contundente de que la duna ha sido fijada por la vegetación hasta el punto de que no resulta necesaria para garantizar la estabilidad de la playa y la defensa de la costa. Vid. STS de 5 de diciembre de 2013.

${ }^{69}$ Vid. RODRÍGUEZ GONZÁLEZ, M. P., El dominio público marítimo-terrestre: titularidad y sistema de protección, Marcial Pons, Madrid, 1999, p. 75; y GONZÁLEZ SALINAS, J., Régimen actual de la propiedad en las costas, Civitas, Madrid, 2000, p. 99.

${ }^{70}$ NÚÑEZ LOZANO, La reforma ... cit., pp. 34-35.

${ }^{71}$ STC 233/2015.
} 
siempre y cuando la invasión tenga lugar por causas distintas a las previstas en el último párrafo del art. 3.1 a), y en todo caso siempre que los terrenos inundados sean navegables".

Por lo tanto, la demanialidad alcanza a los terrenos invadidos por el mar de manera natural, pero sus causas han de ser distintas de la inundación artificial y controlada, aunque se salva el supuesto de los terrenos inundados navegables, que son en todo caso de dominio público marítimo-terrestre con independencia de cuál sea la causa de la inundación, tal y como confirma la disposición adicional décima al regular las urbanizaciones marítimo-terrestres.

Así, la nueva redacción del artículo 4.3 LC plantea la cuestión de cuáles son dichas causas naturales. Como afirma parte de la doctrina, estas causas pueden ser estrictamente naturales o causas naturales inducidas por la acción del hombre, esto es, sin que la intervención humana persiga provocar de modo directo la inundación ${ }^{72}$.

\subsection{Los supuestos singulares}

Como ya hemos visto, la LPUSL redefine el ámbito del dominio público marítimoterrestre, incluso en lo que concierne a la zona marítimo-terrestre y a la playa. Pero, además, la reforma de la LC contempla de manera específica el tratamiento de determinados supuestos, estableciendo reglas singulares que excluyen de la ribera del mar determinadas dependencias y otras para disponer sobre los deslindes, con la finalidad de adecuar la calificación jurídica de determinados espacios a sus propias determinaciones.

Las reglas singulares que reducen el ámbito del demanio son las que se refieren a los terrenos dedicados a actividades de cultivos marinos y a salinas (disposición transitoria 1.5 LC) y a la zona marítimo-terrestre y a la playa de la isla de Formentera (disposición adicional 4 LPUSL). Sobre esta última determinación singular del dominio público, el TC, en la Sentencia 233/2015, pone de relieve la falta de explicación de dicho deslinde

\footnotetext{
${ }^{72}$ MENÉNDEZ REXACH, sobre el artículo $4.3 \mathrm{LC}$ original, parece pronunciarse a favor de las causas naturales. Vid. MENÉNDEZ REXACH, A., "Estudio preliminar. Esquema general del contenido de la Ley y problemas de aplicación", Menéndez Rexach, A., Marcos Fernández, A., Rodríguez-Chaves Mimbrero, B., Bermúdez Sánchez, J. y Chinchilla Peinado, J. A., La Ley de Costas en la Jurisprudencia. Sentencias del Tribunal Constitucional, Ministerio de Medio Ambiente, y Medio Rural y Marino, Madrid, 2010, p. 53. La misma postura sostiene al analizar el texto del Anteproyecto GARCÍA PÉREZ, M., "La reforma de la Ley de Costas: un lobo con piel de cordero", El Cronista del Estado Social y Democrático de Derecho, núm. 31, 2012, p. 65.
} 
en la exposición de motivos así como en el informe de la Dirección General de Sostenibilidad de la Costa y del Mar que acompaña a las alegaciones del abogado del Estado. Además, considera "que las alusiones a la desproporción que supone la parte de superficie demanial respecto de otras islas, o su innecesaridad para garantizar la defensa de la costa, no son argumentos válidos para alterar conceptos constitucionales referidos a una realidad física delimitada en atención a sus características naturales, y no a categorías jurídicas (STC 149/1991, FJ 8), ni tampoco, cabe añadir ahora, a su mayor o menor funcionalidad". Por consiguiente, el TC considera esta disposición inconstitucional al carecer de justificación racional, ya que: "Por imperativo del art. 132.2 CE, los elementos abstractos definitorios de la zona marítimo-terrestre o las playas forzosamente han de ser los mismos en el conjunto del territorio, peninsular o insular, pues la libertad de configuración del legislador tiene, entre otros límites, el que deriva de la concepción unitaria e indivisible de las categorías genéricas de los bienes que conforman el demanio natural ${ }^{73}$,.

Los supuestos singulares que disponen sobre el deslinde son los que se refieren a los paseos marítimos ${ }^{74}$ y a la exclusión de determinados núcleos de población del dominio público marítimo-terrestre, correspondientes a los que se enumeran en el anexo de la Ley y en la extensión que se fija en la planimetría incorporada en el propio anexo (disposición adicional 7 LPUSL) ${ }^{75}$. Esta exclusión y las reglas especiales de deslinde son consideradas por parte de la doctrina como el "talón de Aquiles" de la LPUSL por tratarse de una ley singular que no cumple los parámetros de constitucionalidad que viene exigiendo para este tipo de normas el Tribunal Constitucional ${ }^{76}$.

\footnotetext{
${ }^{73}$ FJ $12 .^{\circ}$.

${ }^{74}$ La disposición adicional 3 LPUSL incorpora un mecanismo ad hoc para deslindar los paseos construidos entre la entrada en vigor de la LC y la LPUSL. De este modo, la línea exterior de los paseos marítimos construidos por la Administración general del Estado o por otras administraciones públicas con la autorización de aquella durante ese período se entiende con carácter general como línea interior de la ribera del mar. AGUIRRE I FONT afirma que en cualquiera de los casos del precepto reformado tampoco se evita que en el futuro se dé un agravio similar a los planteados con la LC, porque la vigencia de la disposición se limita a los paseos construidos o modificados entre el 29 de julio de 1988 y el 30 de mayo de 2013. Vid. AGUIRRE I FONT, “L'impacte...” cit., p. 146.

${ }^{75}$ Como afirma AGUIRRE I FONT, desde la perspectiva constitucional plantea un agravio de difícil justificación constitucional, ya que la exclusión no afecta a núcleos de población que se encuentran en las mismas circunstancias. En este sentido, "sería deseable buscar otras alternativas jurídicas para encajar la problemática específica de estos espacios, y en cualquier caso que la solución adoptada fuera de aplicación general a todos los municipios con la misma problemática". Vid. AGUIRRE I FONT, "L'impacte..." cit., p. 147

${ }^{76}$ SANZ LARRUGA, F. J., "La reforma de la Ley de Costas o la puesta en valor económico del litoral”, López Ramón, F. (coord.), Observatorio de Políticas Ambientales 2014, Thomson Reuters-Aranzadi,
} 
No obstante, sobre esta disposición, el TC afirma que su virtualidad radica en la identificación, "ope legis, de unos terrenos que notoriamente han perdido por obra de la acción del hombre las características de dominio público natural, excluyéndose la necesidad de esa justificación, que según su propio apartado 4 no implica la efectividad inmediata de la exclusión, siendo sólo el presupuesto para la iniciación del expediente que, en su caso, puede terminar con su desafectación”. Por consiguiente, el TC efectúa una interpretación conforme de la exclusión de determinados núcleos de población del dominio público marítimo-terrestre, señalando que su "recto entendimiento" no comporta la inaplicación del completo régimen jurídico previsto por la Ley para la desafectación de aquellos bienes de dominio público que hubieran "perdido las características naturales que determinaron su inclusión en el dominio público marítimoterrestre en virtud de deslindes anteriores”. Considera que la Ley se limita a identificar dichos núcleos de población, pero no excluye "la verificación, en cada caso, de que dicha pérdida determina también que ya no son necesarios para la protección utilización del dominio público", operaciones que "requieren la adopción de las correspondientes resoluciones administrativas", siempre susceptibles, además, de control jurisdiccional ${ }^{77}$.

\section{MECANISMOS PARA PROTEGER LOS BIENES QUE FORMAN PARTE DEL DOMINIO PÚBLICO}

Como ya se ha analizado, la protección de la ribera del mar se basa en su declaración como dominio público así como en la delimitación de los bienes que forman parte de este demanio. Pero la LC establece una serie de mecanismos que, de forma más o menos directa, se traducen en una garantía más efectiva y adecuada de la integridad y conservación del dominio público litoral. Algunos de estos son las llamadas limitaciones a las propiedades privadas colindantes con la zona de demanio y las reglas para la utilización y ocupación previstas en la Ley para dicho demanio.

Cizur Menor, 2014, p. 467. En este sentido, vid. MENÉNDEZ REXACH, A., "La nueva regulación de las costas: un giro hacia el dominio privado marítimo-terrestre”, Carro Fernández-Valmayor, J. L., Ferreira Fernández, J. y Nogueira López, A. (coords.), La nueva regulación de las costas: actas del IX Congreso de la Asociación Española de Profesores de Derecho Administrativo, INAP, Madrid, 2014, pp. 13-55.

77 STC 233/2015, FJ $14 .^{\circ}$. 


\section{Limitaciones al derecho de propiedad sobre los terrenos adyacentes a la ribera}

\section{del mar}

La protección del dominio público marítimo-terrestre no puede alcanzarse únicamente mediante una acción eficaz sobre la zona que ostenta esta calificación jurídica, sino que —como establece la propia exposición de motivos de la Ley_ "resulta imprescindible la actuación sobre la franja privada colindante, para evitar que la interrupción del transporte eólico de los áridos y el cierre de las perspectivas visuales para la construcción de edificaciones en pantalla, la propia sombra que proyectan los edificios sobre la ribera del mar, el vertido incontrolado y, en general, la incidencia negativa de la presión edificatoria y de los usos y actividades que ella genera sobre el medio natural, puedan causar daños irreparables o de muy difícil y costosas reparaciones".

\subsection{Conjunto de limitaciones y servidumbres}

Con el fin de preservar el dominio público marítimo-terrestre y teniendo en cuenta la función social de la propiedad privada que la CE reconoce en el artículo 33.2, el artículo 21 LC prevé la sujeción de las propiedades colindantes con el demanio a un conjunto de limitaciones y servidumbres ${ }^{78}$ que prevalecerán frente a la interposición de cualquier título y que serán imprescriptibles en todo caso $^{79}$. Estas son las siguientes: la servidumbre de protección; la servidumbre de tránsito; la servidumbre de acceso al mar; y la zona de influencia. Analizamos a continuación la incidencia de la LPUSL sobre la servidumbre de protección.

\section{A. La servidumbre de protección}

\footnotetext{
${ }^{78}$ BLASCO DÍAZ, J. L., Régimen jurídico de las propiedades particulares en el litoral, Tirant lo Blanch, Valencia, 1999, p. 207 y ss.; RODRÍGUEZ GONZÁLEZ, M. P., El dominio público marítimo-terrestre: titularidad y sistemas de protección, Marcial Pons, Madrid, 1999; MORENO MOLINA, A. M., "Otras servidumbres y limitaciones de propiedad”, Pérez Gálvez, J. F. (dir.), El nuevo derecho de costas, Bosch, Barcelona, 2014, pp. 625-664; OLANO ESPINOSA, C., "Servidumbre de protección y otras limitaciones legales", Torres-Fernández Nieto, J. J., Fernández de Trocóniz, F. C., Olano Espinosa, C., Menéndez Menéndez, A., González de Olano, G., Cancer Minchot, P. y Risquete, J. L., Comentario a la Ley 2/2013, de 29 de mayo, de Protección y Uso Sostenible del Litoral y de Modificación de la Ley 22/1988, de Costas, Thomson Reuters Aranzadi, Cizur Menor, 2014, pp. 217-249.

${ }^{79}$ El TC admitió la constitucionalidad de estas limitaciones de la propiedad sobre la base del artículo 149.1.13 CE, ya que tales terrenos forman parte del demanio, pero sí son necesarias aquellas limitaciones para proteger la integridad y características de este. STC 149/1991, de 4 de julio, FJ 3. ${ }^{\circ}$.
} 
La servidumbre de protección recae sobre un espacio de 100 metros desde el límite interior de la ribera del mar, susceptible de ser ampliado por la Administración general del Estado, de acuerdo con la de la Comunidad Autónoma y el ayuntamiento correspondientes, hasta un máximo de 100 metros más ${ }^{80}$.

Sobre la posibilidad de extensión de la servidumbre de protección en 100 metros, el TC ha declarado su constitucionalidad justificándola "en la competencia del Estado para dictar la legislación básica sobre protección del medio ambiente que, en este caso, necesariamente se ha de traducir en una habilitación a la potestad ejecutiva de la Administración del Estado para, según las posibilidades del tramo de costa de que se trate, adoptar la decisión más adecuada y conveniente a fin de asegurar la efectividad de la servidumbre. Tal habilitación no resulta contraria al carácter básico de la norma, ni mucho menos vulnera el ámbito competencial autonómico, una vez que, en todo caso, es preciso el acuerdo de la Comunidad Autónoma y del Ayuntamiento correspondiente" ${ }^{\prime 81}$. Así, en la STC 149/1991 se ratificó la constitucionalidad del artículo 23 LC al considerar que la fijación de una banda de anchura uniforme es el modelo tradicional de establecer la delimitación de la zona de servidumbre contigua a la marítima-terrestre, con independencia de cuál sea la anchura que se le asigna. Pero en la STC 233/2015, relativa a la modificación de la LC, el Tribunal afirma que la misma ratio de la Sentencia citada anteriormente le conduce a declarar la conformidad constitucional del nuevo artículo 23.3 LC: "La fijación de la zona de servidumbre de protección en 100 metros como regla general era y es compatible con el establecimiento, en más, pero también en menos, de márgenes de flexibilidad que tengan en cuenta la realidad preexistente (disposición transitoria $3^{\mathrm{a}} \mathrm{LC}$ ) o las diversas características físicas de cada tramo de la costa. En los propios términos de la STC 149/1991, la variedad de las condiciones físicas de la costa hace razonable, e incluso impone, que no sean idénticas las normas que hayan de aplicarse en uno u otro sitio para la protección del medio ambiente litoral y para asegurar la utilización del demanio, o tal vez, más precisamente, que la estructura jurídicamente uniforme de la protección y de la libertad de acceso (limitaciones a la propiedad, servidumbres de acceso y tránsito) se

\footnotetext{
${ }^{80}$ Artículos 23 a 26 LC.

${ }^{81}$ FJ 3 D.
} 
haga compatible con una acomodación de las determinaciones normativas a la diversidad natural [FJ 3.C)]",

Otro aspecto polémico de la LPUSL es la reducción, en determinados supuestos, de la servidumbre de protección de la LC. En este sentido, el nuevo apartado 3 del artículo 23 LC permite reducir la servidumbre de protección de 100 a 20 metros en los márgenes de los ríos hasta donde sean sensibles a las mareas, en atención a las características geomorfológicas, a sus ambientes de vegetación y a su distancia respecto a la desembocadura. El régimen de utilización de esta zona se determina mediante la aplicación de diferentes reglas. En primer lugar, en los primeros 20 metros se permite la realización de operaciones de salvamento marítimo y el depósito temporal de objetos o materiales arrojados por el mar. También se podrán realizar, sin necesidad de autorización, cultivos y plantaciones. Sin embargo, con carácter ordinario, exclusivamente se permiten las obras, instalaciones y actividades que, por su naturaleza, no puedan tener otra ubicación o presten servicios necesarios para la utilización del dominio público marítimo-terrestre, así como las instalaciones deportivas abiertas. En segundo lugar, se prohíben, según el artículo 25.1 de la LC, los siguientes usos: edificaciones destinadas a residencia o habitación; construcción o modificación de vías de transporte interurbanas y de alta intensidad de tráfico; actividades que impliquen la destrucción de yacimientos de áridos naturales o no consolidados ${ }^{83}$; líneas eléctricas de alta tensión; vertido de residuos sólidos y aguas residuales sin depuración; y la publicidad a través de carteles o vallas o por medios acústicos o audiovisuales.

En cuanto a la publicidad de las instalaciones o actividades permitidas en la zona de servidumbre, la LPUSL incorpora un nuevo apartado 4 en el artículo 25 LC a fin de

\footnotetext{
${ }^{82} \mathrm{FJ} 4 .^{\circ}$.

${ }^{83}$ La nueva redacción del artículo 25.1 c) LC cambia el régimen de prohibición de las actividades que impliquen la destrucción de yacimientos de áridos. Así, la prohibición anterior a la reforma se limita ahora a los "yacimientos de áridos naturales o no consolidados, entendiéndose por tales los lugares donde existen acumulaciones de materiales detríticos tipo arenas o gravas". Además, como excepción a la prohibición del artículo $25.1 \mathrm{f}$ ), el nuevo apartado 4 del artículo $25.1 \mathrm{LC}$ remite al reglamento el establecimiento de las condiciones en las que se podrá autorizar la publicidad, "siempre que sea parte integrante o acompañe a instalaciones o actividades permitidas y no sea incompatible con la finalidad de la servidumbre de protección". Sobre esta reforma, el TC considera que la nueva regulación no desprotege en su integridad los yacimientos de áridos al mantener la prohibición de las actividades que impliquen la destrucción de los naturales o no consolidados. Además, resalta que la prohibición recogida en el artículo $25 \mathrm{LC}$ se predica de la destrucción, pero no impide toda actividad extractiva. De esta forma, el TC afirma que "se trata pues de una actividad lícita antes y después de la reforma legal, si bien sometida a importantes restricciones a fin de evaluar debidamente sus efectos en el dominio público marítimo-terrestre y, en particular, para salvaguardar la integridad de la playa". STC de 5 de noviembre de 2015 , FJ 5. .
} 
introducir una excepción a la prohibición general de publicidad en la zona de servidumbre de protección. El citado precepto remite al reglamento para el establecimiento de las condiciones en las que se podrá autorizar la publicidad, "siempre que sea parte integrante o acompañe a instalaciones o actividades permitidas y no sea incompatible con la finalidad de la servidumbre de protección”.

Sobre esta reforma, el TC afirma que no supone una novedad absoluta, ya que la publicidad admitida en estos casos tiene un antecedente en el artículo 45.5 RC. Además, considera que este tipo de regulaciones están comprendidas en la "libertad de configuración del legislador, que se proyecta con mayor intensidad cuando se trata de regular no ya el régimen de los bienes de dominio público marítimo-terrestre, que en sus líneas maestras figura en el art. $132 \mathrm{CE}$ como límite infranqueable, sino las limitaciones que afectan a los predios sitos en la franja adyacente; los terrenos contiguos a la ribera del mar" 84 .

Además, el Tribunal considera que las prohibiciones referidas a la zona de servidumbre de protección que tienen la finalidad de proteger los valores naturales y paisajísticos del demanio, como las comentadas sobre publicidad, son "normas de legislación básica de protección del medio ambiente (art. 149.1.23 CE), motivo por el cual el precepto citado no vulnera las competencias autonómicas en materia de ordenación del territorio y urbanismo". Pero tampoco esta regulación invade la competencia autonómica en materia de publicidad, porque el "precepto [...] no tiene la finalidad de regular el sector publicitario sino de introducir una limitada modulación a la prohibición general de publicidad en la zona de servidumbre de protección, prohibición que responde a finalidades medioambientales $[\ldots]^{\prime, 85}$.

En definitiva, el régimen de utilización de esta zona implica un conjunto importante de limitaciones para los propietarios adyacentes a la zona de dominio público. Sin embargo, este régimen proteccionista y avanzado que diseña la LC debe relativizarse, básicamente por dos motivos. Por una parte, hay que tener en cuenta que la extensión de esta zona se verá reducida a 20 metros en suelo urbano o urbanizable programado que ya tenga un plan parcial aprobad ${ }^{86}$. Esto implica que la zona de servidumbre de

\footnotetext{
${ }^{84}$ STC 233/2015, FJ 5. ${ }^{\circ}$.

${ }^{85}$ STC 6/2016, FJ 4 b.

${ }^{86}$ La disposición transitoria primera de la LPUSL establece el régimen de aplicación de la disposición transitoria tercera LC, que a su vez determina el régimen aplicable a los terrenos que a su entrada en vigor
} 
protección únicamente tendría plena efícacia sobre el suelo clasificado como no urbanizable o urbanizable no programado. Por otra, la LC admite que el Consejo de Ministros, con carácter excepcional y por razones de utilidad pública, autorice la construcción o modificación de vías de transporte interurbanas y las de intensidad de tráfico superior a la que se determine reglamentariamente y de líneas eléctricas de alta tensión. También podrán ser autorizadas las edificaciones destinadas a residencia y habitación y las instalaciones industriales cuando por razones económicas sea conveniente su ubicación en el litoral, siempre que en ambos casos se localicen en zonas de servidumbre correspondientes a tramos de costa que no constituyan playa ni zonas húmedas u otros ámbitos de especial protección.

\subsection{Determinadas reglas para la ocupación del dominio público marítimo-terrestre}

Una de las finalidades más importantes de la demanialización de la ribera del mar es asegurar el uso libre, público y gratuito de dichos bienes demaniales para todos los ciudadanos.

Pero la LC regula detalladamente el régimen de usos del dominio público marítimoterrestre para garantizar la utilización racional de este espacio y evitar que un exceso de usos pueda deteriorar su integridad física o dañar aquel uso común y general ${ }^{87}$.

A estos efectos, prevé diferentes formas de utilización tanto por parte de la Administración como de los particulares. Desde la primera perspectiva, la LC contempla la posibilidad de reserva a la Administración general del Estado cuando la utilización de estos bienes sea necesaria para determinadas instalaciones, obras o servicios públicos, y la adscripción de parcelas del litoral a las comunidades autónomas para puertos y vías de transporte.

estaban clasificados como suelo urbano. El TC, en la reciente Sentencia 6/2016, vuelve a destacar que lo previsto en dicha disposición supone la vulneración de las competencias autonómicas en materia de ordenación del territorio y urbanismo, reiterando el criterio de la STC 233/2015 (FJ 16. ${ }^{\circ}$ ), en la cual se remite a la STC 149/1991, FJ 8 d) y a las SSTC 198/1991, de 17 de octubre, 87/2012, de 18 de abril, 137/2012, de 19 de junio, 34/2014, de 27 de febrero, y 5/2015, de 22 de enero.

${ }^{87}$ Véanse los artículos 31 y siguientes LC. Como afirman VILLANUEVA CUEVAS, PUNZÓN MORALES y SÁNCHEZ RODRÍGUEZ, la regulación de los usos debe ser entendida como "un mecanismo para proteger la integridad del mismo, de manera que siempre prevalezca la protección ambiental de la ribera del mar frente a la utilización de la misma, sea cual sea el tipo de uso del que se esté hablando [...]”. Vid. VILLANUEVA CUEVAS, PUNZÓN MORALES y SÁNCHEZ RODRÍGUEZ, “La protección...” cit., p. 623. 
Desde la segunda, la LC diferencia entre: uso común general, que permite la utilización libre, pública y gratuita del dominio público marítimo-terrestre para usos comunes (pasear, bañarse, navegar, pescar, etc.); uso común especial, en el que, sin impedir el uso de otros, concurren circunstancias de especial intensidad, peligrosidad o rentabilidad que hacen necesaria la obtención previa de una autorización administrativa, de carácter personal e intransferible inter vivos y por una duración máxima de cuatro años, excepto si la LC establece lo contrario; y uso privativo, que, en la medida en que implica la ocupación del demanio marítimo con obras o instalaciones fijas $\mathrm{y}$ permanentes, con exclusión de la utilización por otras personas, está sujeto a concesión administrativa previa, otorgada por la Administración general del Estado y sin que pueda superar los 75 años $^{88}$. Además, hay que tener en cuenta que únicamente se permite la ocupación del dominio público para aquellas actividades o instalaciones que por su naturaleza no puedan tener otra ubicación.

Asimismo, el artículo 33 LC recoge una serie de medidas concretas destinadas a proteger y garantizar el uso público de todas las playas del litoral. Además, el nuevo artículo 33.6 LC introduce la distinción entre tramos naturales y urbanos de las playas. Ambos tipos de playas habrán de delimitarse con la participación de las administraciones competentes en materia de ordenación del territorio y urbanismo. En las "playas urbanas" el nivel de protección será menor, y la Ley ya contempla expresamente que "podrá autorizarse la celebración de aquellos eventos de interés general con repercusión turística que se establezcan", lo que supone una vía abierta a la explotación mercantil de las playas en detrimento evidente de su conservación medioambiental.

Esta regulación da lugar a conflictos competenciales, pues varias comunidades autónomas han aprobado planes de ordenación del litoral y algunas, como Cataluña o Andalucía, han incorporado a sus estatutos de autonomía la competencia exclusiva para el establecimiento y la regulación de los planes territoriales de ordenación del uso del litoral y de las playas. La Generalitat de Catalunya impugnó esta regulación, mediante la interposición del recurso de inconstitucionalidad 4912-2013, al considerar vulnerada su competencia en materia de ordenación del territorio y del litoral, formulando tres quejas al respecto. La primera es que, al admitir la celebración de eventos de interés general con repercusión turística en los tramos urbanos de las playas, establece una

\footnotetext{
${ }^{88}$ La LPUSL aumenta el plazo máximo de 30 a 75 años.
} 
norma relativa a los usos del suelo que excede del artículo 149.1.23 CE. La segunda se refiere a la remisión al reglamento estatal del régimen de ocupación y uso de los tramos naturales y urbanos de las playas. Y la tercera cuestiona la reserva estatal para la delimitación de los tramos urbanos y naturales de las playas, pues esa delimitación debería hacerse por remisión a la clasificación urbanística otorgada a los terrenos contiguos a la playa.

Sobre la distinción entre tramos naturales y urbanos de las playas, en la STC 233/2015, de 5 de noviembre de 2015, el Tribunal ya descartó que resultase contraria al artículo 132.2 CE y al artículo 9.3 CE, manifestando que dicha distinción no afecta a su naturaleza demanial sino al régimen de usos de estos bienes y que "no puede calificarse de irrazonable que la determinación de los usos admisibles en las playas tenga en cuenta el grado de urbanización del entorno en el que se desenvuelven, y module en consecuencia el régimen de ocupación y uso atendiendo a su naturaleza, dotando a los tramos naturales de las playas de un elevado nivel de protección que restrinja su ocupación. Tampoco cabe apreciar que esta reforma suponga un giro copernicano, si atendemos a lo dispuesto en el artículo 33 LC 1988, que fijó criterios indistintos para el uso y ocupación del conjunto de las playas, con un considerable margen de flexibilidad" $" 89$.

En relación con la primera de las quejas formuladas por la Generalitat de Catalunya, el Tribunal Constitucional considera que el precepto no determina cuál ha de ser el régimen concreto de utilización y ocupación del demanio ni impone un uso concreto. Se trata, por lo tanto, "de una norma que concurre a definir los límites dentro de los que puede ejercerse la competencia autonómica de ordenación del litoral, disponiendo que el nivel de protección necesario en determinados tramos de playa no impone proscribir ese preciso uso, dejando intacto, sin embargo, el margen de apreciación de las instancias autonómicas o, en su caso, locales, para preverlo o no. Al no ser, por lo ya expuesto, una norma que fije usos para un ámbito territorial, sino un precepto que enmarca las decisiones normativas autonómicas y municipales sobre dichos usos, resulta acorde con la doctrina de este Tribunal y, en consecuencia, constitucional"90.

\footnotetext{
${ }^{89}$ STC de 5 de noviembre de 2015 , FJ 6. ${ }^{\circ}$.

${ }^{90}$ STC 28/2016, de 18 de febrero de 2016, FJ 3. ${ }^{\circ}$.
} 
En cuanto a la remisión reglamentaria recogida en el precepto, se considera que desborda lo constitucionalmente admisible porque habilita al Estado para regular el régimen global de ocupación y uso de las playas, apartándose de la limitación, determinada por el Tribunal Constitucional en la Sentencia 149/1991, de establecer unos máximos y mínimos. Pero sobre esta cuestión, el Tribunal Constitucional afirma que "el Estado está obligado a proteger el demanio marítimo-terrestre a fin de asegurar tanto el mantenimiento de su integridad física y jurídica, como su uso público y sus valores paisajísticos" ${ }^{\prime 91}$. Además, añade que, por el carácter marcadamente preventivo del nuevo apartado 6 del artículo 33 LC, "no podemos acoger el reproche de inconstitucionalidad fundado únicamente en la habilitación legal para su desarrollo reglamentario, ya que es doctrina consolidada que tal habilitación no puede ser calificada per se como vulneradora de las competencias autonómicas, en este caso en materia de ordenación del territorio y urbanismo. Resta añadir que, no siendo tal desarrollo reglamentario el objeto de este proceso 'nada impide que, si el Gobierno, al dictar las correspondientes normas reglamentarias en virtud de esa remisión, extendiera su regulación a aspectos no básicos, pudiera plantearse el oportuno conflicto de competencias a fin de examinar si se hubiera producido o no la extralimitación en el ámbito competencial estatal' (STC 161/2014, de 7 de octubre, FJ 9)"92. A esto añade en la STC 28/2016, de 18 de febrero, que es doctrina consolidada que tal habilitación "no puede ser calificada per se cómo vulneradora de las competencias autonómicas, en este caso en materia de ordenación del territorio y urbanismo. [...] el art. 33.6 LC no es una norma que disponga los usos del territorio, sino un precepto que señala los límites que, por motivos ambientales (149.1.23 CE) o de tutela de la titularidad demanial (132.2 CE) deben ser respetados por quien, en actuación de la competencia urbanística o de ordenación territorial decide sobre los mencionados usos".

Y en relación con la reserva estatal para la delimitación de los tramos, el Tribunal Constitucional considera que este precepto "tiene una clara finalidad protectora del demanio y en nada incide en la competencia urbanística para clasificar los suelos [...]. Los órganos autonómicos y locales, en la medida de su respectiva competencia, podrán realizar esta atribución cómo tengan por conveniente. Lo que se sigue del planteamiento de los recurrentes es una pretensión de que la clasificación urbanística de los terrenos

\footnotetext{
${ }^{91}$ STC 6/2016, FJ 4b. En el mismo sentido ya se pronunció el TC en la Sentencia 233/2015, FJ 6. ${ }^{\circ}$.

${ }^{92}$ STC 6/2016, FJ 4 b.
} 
colindantes a la playa, se proyecte más allá del ámbito que le es propio, afectando al nivel de protección de las playas. Pero esa es una opción, no la única posible, puesta a disposición del legislador competente, el cual, en efecto, ha optado por un criterio de catalogación de los tramos naturales y urbanos de las playas a realizar por la Administración competente en materia de ordenación del territorio, que tiene en cuenta la situación de los terrenos colindantes (art. 67 del Real Decreto 876/2014, de 10 de octubre, por el que se aprueba el Reglamento general de costas)" ${ }^{\text {"93. }}$.

La LC regula las diferentes formas de utilización privativa del dominio público marítimo-terrestre, distinguiendo entre reservas y adscripciones, por una parte, y autorizaciones y concesiones, por otra. Las primeras consisten en la utilización privativa del demanio por parte del Estado - reservas - o de las CC. AA. —adscripcionespara el cumplimiento de fines propios de aquel o para la construcción de nuevos puertos o vías de transporte de titularidad de la comunidad autónoma o la modificación de las existentes $^{94}$.

En cuanto a la regulación de las autorizaciones y concesiones, las primeras se otorgarán para usos que, sin implicar ocupación del demanio, conlleven especial intensidad, rentabilidad o peligrosidad, o que, pese a ocuparlo, lo hagan mediante instalaciones desmontables o bienes muebles (art. 51 LC). Sin embargo, toda ocupación con instalaciones no desmontables se sujeta a la concesión administrativa previa ${ }^{95}$.

En el caso de las autorizaciones, el plazo máximo de vencimiento será el que se determine en el título correspondiente y no podrá exceder de cuatro años, salvo en los casos en que la propia LC establezca otro diferente ${ }^{96}$. Además, las autorizaciones podrán ser revocadas unilateralmente por la Administración en cualquier momento, sin derecho a indemnización, cuando produzcan daños en el dominio público, impidan su

\footnotetext{
${ }^{93}$ STC 28/2016, de 18 de febrero de 2016, FJ 3. ${ }^{\circ}$.

94 Artículos 47 a 50 LC.

${ }^{95}$ Para un estudio de las concesiones y autorizaciones de dominio público marítimo-terrestre más exhaustivo, véanse VILLALBA PÉREZ, F., "Concesiones y autorizaciones de dominio público marítimoterrestre en el Real Decreto 876/2014, de 10 de octubre, por el que se aprueba el Reglamento General de la Ley de Costas", Pérez Gálvez, J. F. (dir.), El nuevo derecho de costas, Bosch, Barcelona, 2014, pp. 665-743; MENÉNDEZ MENÉNDEZ, A. y GONZÁLEZ DE OLANO, C., "La reforma y el régimen de las autorizaciones y concesiones", Torres-Fernández Nieto, J. J., Fernández de Trocóniz, F. C., Olano Espinosa, C., Menéndez Menéndez, A., González de Olano, G., Cancer Minchot, P. y Risquete, J. L., Comentario a la Ley 2/2013, de 29 de mayo, de Protección y Uso Sostenible del Litoral y de Modificación de la Ley 22/1988, de Costas, Thomson Reuters Aranzadi, Cizur Menor, 2014, pp. 251-301.

${ }^{96}$ Artículo 52.4 LC, modificado por la LPUSL, que amplía el plazo de 1 a 4 años.
} 
utilización para actividades de mayor interés público o menoscaben el uso público, cuando los terrenos ocupados soporten un riesgo cierto de que el mar los alcance y cuando resulten incompatibles con la normativa aprobada con posterioridad. En este último caso, solo se revocará la autorización si, en el plazo de tres meses desde que fuera comunicada tal circunstancia a su titular, este no hubiera adaptado su ocupación a la nueva normativa o la adaptación no fuera posible física o jurídicamente ${ }^{97}$.

En cuanto a las concesiones, estas se otorgan sin perjuicio de terceros y dejando a salvo los derechos preexistentes y no podrán superar los 75 años ${ }^{98}$. La LPUSL modifica el apartado 2 del artículo 66 LC y amplía notablemente la duración de las concesiones

\footnotetext{
${ }^{97}$ Esto se ha introducido con la modificación incorporada por la LPUSL y ha sido objeto de impugnación en el recurso de inconstitucionalidad interpuesto por el Consejo de Gobierno de Andalucía. El TC examina el precepto y concluye que debe interpretarlo del mismo modo que en su redacción original. Así, se remite a la STC 14/1991, en la que concluyó que "la revocación de una autorización por resultar incompatible con la normativa aprobada con posterioridad es, en sí, una previsión legal que se limita a establecer el régimen de las autorizaciones demaniales, cuya aprobación no se ha discutido al legislador estatal. Ahora bien, si la normativa cuya aprobación da lugar a la revocación de la autorización debe ser ejecutada por la Comunidad Autónoma, al margen de que venga establecido por las leyes estatales o autonómicas, será ésta la que habrá de resolver si se debe o no impedir que continúe la utilización autorizada en su día, de manera que la resolución dictada por la Administración del Estado queda en cierto sentido vinculada por la resolución autonómica dictada en el ejercicio de sus competencias ejecutivas sectoriales" (STC 6/2016, FJ 4d).

${ }^{98}$ Sobre esta prórroga recogida en la nueva regulación, el TC afirma lo siguiente: “(i) sólo puede afectar a las actividades o instalaciones que, por su naturaleza, no puedan tener otra ubicación (art. 32.1 LC); (ii) llegado el momento de la extinción de la concesión, es la Administración la que decide sobre el levantamiento o mantenimiento de las obras e instalaciones, pudiendo dar continuidad a su explotación o utilización (art. 72.1 y 3); (iii) las exigencias medioambientales no sólo quedan cubiertas por el informe autonómico exigido por este precepto, pues, de acuerdo con las competencias asumidas por las Comunidades Autónomas para el desarrollo legislativo y ejecución en materia de medio ambiente, les corresponde el otorgamiento de la autorización ambiental integrada y su revisión, según dispone la citada Ley 16/2002; y (iv) en último término, la concesión demanial está configurada como un título de ocupación del dominio público, no como medida de intervención en garantía de leyes sectoriales que recaigan sobre la actividad, lo que impide que la Administración del Estado pueda ejercer su facultad de concesión demanial para interferir o perturbar el ejercicio de las potestades de las Comunidades Autónomas en aquellos ámbitos materiales sobre los que ostentan competencias de ejecución, de acuerdo con los parámetros que expuso la STC 77/1984" (STC 149/1991, FJ 4.G.a), con cita del artículo 65 LC) FJ $10{ }^{\circ}$. De este modo, el TC rechaza la argumentación de los recurrentes, basada en la presunta contradicción de la norma con la Directiva 2006/123/CE del Parlamento Europeo y del Consejo, de 12 de diciembre de 2006, relativa a los servicios en el mercado interior, y otras leyes, manifestando que la concesión demanial está configurada como un "título de ocupación del dominio público, no como medida de intervención en garantía de leyes sectoriales que recaigan sobre la actividad [STC 149/1991, FJ 4.G.a]. Será pues esta legislación sectorial la que discipline las actividades empresariales de las que la concesión demanial resulta ser únicamente el soporte físico y, señaladamente, la legislación ordenada a la defensa de la libertad de competencia, mediante la prevención y, en su caso, la represión de las situaciones que constituyen obstáculos creados por decisiones empresariales para el desarrollo de la competencia en el mercado (STC 108/2014, de 26 de junio, FJ 3. ․, y las allí citadas)”, FJ 10.c).
}

Sobre el cómputo del plazo, MENÉNDEZ REXACH afirma que obedece a la suma del plazo inicialmente concedido más la prórroga, por lo que estaríamos ante una duración de la concesión de unos cien años. Vid. MENÉNDEZ REXACH, A., "La nueva regulación de las costas. Un giro hacia el dominio privado marítimo-terrestre", ponencia presentada en el IX Congreso de la Asociación Española de Profesores de Derecho Administrativo, Santiago de Compostela, 2014, p. 43. 
sobre el dominio público marítimo-terrestre, que pasan de los 30 años que como máximo permitía esta a un período que no podrá exceder de los 75 . Según la exposición de motivos de la LPUSL, que califica esta prórroga de extraordinaria, la finalidad de la medida legal es dar respuesta a la extinción de las concesiones que comenzarían a expirar en 2018, buscando la estabilización de derechos y su adaptación a un horizonte temporal semejante al nuevo plazo máximo de duración de las concesiones demaniales, que pasa de treinta a setenta y cinco años. Pero, además, la propia exposición de motivos subraya que no se trata de una prórroga indiscriminada, dado que para las concesiones que amparen usos destinados a instalaciones e industrias incluidas en el ámbito de aplicación de la Ley 16/2002, de 1 de julio, de Prevención y Control Integrados de la Contaminación, se exige el informe del órgano ambiental autonómico. Su otorgamiento podrá conllevar la declaración de utilidad pública a efectos de ocupación temporal o expropiación forzosa de los bienes o derechos afectados por aquella, incorporándose los bienes y derechos expropiados al dominio público marítimo-terrestre en los términos establecidos en la concesión. Además, las concesiones serán transmisibles por actos inter vivos y mortis causa. Pero la transmisión inter vivos ${ }^{99}$ solo será válida si con carácter previo la Administración reconoce el cumplimiento, por parte del adquirente, de las condiciones establecidas en la concesión (art. 70.2 LC).

\section{CONCLUSIONES}

Como hemos comprobado, sobre el espacio litoral concurren una serie de competencias que corresponden a las diferentes administraciones actuantes. Ante este problema de concurrencia de competencias e independientemente de los contenidos que introduce la reforma de la LC en cuanto a la posible invasión competencial, el objetivo de la protección de la costa sigue vinculado a la coordinación y colaboración entre las diferentes administraciones.

\footnotetext{
${ }^{99}$ El artículo 1.22 LPUSL permite la transmisión de estas concesiones tanto por actos inter vivos como mortis causa, aunque supedita la validez de esta primera modalidad al reconocimiento previo por parte de la Administración del cumplimiento por el adquirente de las condiciones establecidas en la concesión. La novedad recae sobre la transmisión inter vivos, ya que la modalidad mortis causa ya se recogía en la LC. No obstante, la novedad de la LPUSL es que amplía a cuatro años el plazo para que los causahabientes comuniquen expresamente a la Administración el fallecimiento del concesionario y la voluntad de subrogarse en su derecho. Vid. ALONSO GARCÍA, M. C., "La legalización, por la modificación de la Ley de Costas de 2013, de un negocio jurídico fraudulento: a propósito de las sentencias del Tribunal Supremo de 5 de noviembre de 2013", Revista Vasca de Administración Pública, núm. 99-100, 2014.
} 
La LPUSL es una norma controvertida que está teniendo un fuerte impacto en el régimen de la costa, por lo que ha sido recurrida desde varias instancias ante el TC. Como hemos analizado, la STC 233/2015 ha estimado de forma parcial el recurso de inconstitucionalidad presentado. Pero es importante resaltar que el Tribunal ha desestimado la mayor parte de las presuntas vulneraciones alegadas y avala la constitucionalidad de la nueva regulación de la LC en relación con: la remisión al reglamento de la concreción de los criterios que fijan los límites de la zona marítimoterrestre; la exclusión de dicha zona de los terrenos que sean inundados artificial y controladamente, siempre que estos no fueran de dominio público antes de la inundación; la fijación de una anchura de 20 metros para las zonas de playa, en tramos naturales y urbanos; la prórroga de las concesiones demaniales; y la exclusión del dominio público de aquellas zonas de las urbanizaciones marítimo-terrestres destinadas a estacionamientos náuticos ${ }^{100}$.

En términos similares se ha pronunciado el TC en la Sentencia 6/2016, de 21 de enero de 2016, y en la Sentencia 28/2016, de 18 de febrero. En relación con la mayoría de las impugnaciones, el Tribunal las desestima y se remite a la argumentación desarrollada en su reciente STC 233/2015, donde se llevó a cabo un enjuiciamiento casi total de la modificación de la LC. En cuanto a las tachas de inconstitucionalidad sobre la posible vulneración de las competencias autonómicas en materia de ordenación del territorio y urbanismo, así como de la autonomía local, el Tribunal invoca su doctrina sobre la titularidad estatal del demanio y la posibilidad de incidir sobre dichas competencias.

Como valoración general, cabe afirmar que las políticas y estrategias de los últimos años para proteger el espacio litoral como la LPUSL, a pesar de fundamentarse en la vulnerabilidad y degradación real de la costa, la realidad es bien distinta, ya que los intereses económicos suelen prevalecer sobre por encima de la real y efectiva tutela medioambiental ${ }^{101}$. Además, las pretensiones de esta norma de reforzar la seguridad

\footnotetext{
${ }^{101}$ Sobre la nueva regulación de los estacionamientos náuticos, véase RIVAS ANDRÉS, R., "Las marinas y el nuevo "estacionamiento náutico" como derecho real, legal y administrativo en la reformada Ley de Costas”, Diario La Ley, núm. 8214, 2013.

${ }^{101}$ En este sentido, MENÉNDEZ REXACH califica la reforma como "un giro hacia el dominio privado marítimo-terrestre", caracterizada "por favorecer sin pudor a grupos de intereses privados en detrimento de la protección del dominio público marítimo-terrestre y su destino normal al uso público"; vid. MENÉNDEZ REXACH, A., "La nueva regulación de las costas: un giro hacia el dominio privado marítimo-terrestre", Carro Fernández-Valmayor, J. L., Ferreira Fernández, J. y Nogueira López, A. (coords.), La nueva regulación de las costas: actas del IX Congreso de la Asociación Española de
} 
jurídica se han visto en muchas ocasiones seriamente cuestionadas con la revisión del concepto de dominio público marítimo-terrestre.

\section{BIBLIOGRAFÍA}

AGUIRRE I FONT, J. M., "L'impacte de la reforma de la Llei de Costes sobre el régimen jurídic del litoral català: especial referencia a la reducció de l'espai protegit i a les invasions competencials", Revista catalana de dret públic, núm. 47, 2013.

AGUIRRE I FONT, J. M., El régimen jurídico del litoral catalán. Especial referencia a la reforma de la Ley de Costas operada por la Ley 2/2013 y al nuevo Reglamento General de Costas aprobado por el Real Decreto 876/2014, Atelier, Barcelona, 2014.

AGUIRRE I FONT, J. M., "El legislador autonómico ante la reforma de la ley de costas: la necesidad de articular un nuevo modelo de gestión integrada del litoral", Volumen Recopilatorio de las Actas del IX Congreso de la Asociación de Profesores de Derecho Administrativo de 2014, Instituto Nacional de Administración Pública, Madrid, 2014.

AGUIRRE I FONT, J. M., El régimen jurídico del litoral catalán. Especial referencia a la reforma de la Ley de Costas operada por la Ley 2/2013, de 29 de mayo, de protección y uso sostenible del litoral y de modificación de la Ley 22/1988, de 28 de julio, de Costas, Atelier, Barcelona, 2015.

ALONSO GARCÍA, M. C., "La legalización, por la modificación de la Ley de Costas de 2013, de un negocio jurídico fraudulento: a propósito de las sentencias del Tribunal Supremo de 5 de noviembre de 2013", Revista Vasca de Administración Pública, núm. 99-100, 2014.

ARANA GARCÍA, E., "La Ley 2/2013 de Protección y Uso Sostenible del Litoral: las "soluciones singulares" y las nuevas medidas relativas a los riesgos naturales en la costa", Revista de derecho urbanístico y medio ambiente, núm. 295, 2015, pp. 101-135. ARANA GARCÍA, E. y NAVARRO ORTEGA, A., "La Ley de Protección y Uso Sostenible del Litoral: ¿un giro hacia lo desconocido?, Revista Vasca de Administración Pública, núm. 97, septiembre-diciembre 2013, pp. 21-60.

Profesores de Derecho Administrativo, INAP, Madrid, 2014. 
ARENILLA SÁEZ, M., "El nuevo sistema de competencias locales", Santamaría Pastor, J. A. (coord.), La reforma de 2013 del régimen local español, Fundación Democracia y Gobierno Local, Madrid, 2013.

BELADÍEZ ROJO, M., "Problemas competenciales sobre la zona marítimo-terrestre y las playas", Martín-Retortillo Baquer, S. (coord.), Estudios sobre la Constitución Española. Homenaje al profesor Eduardo García de Enterría, vol. IV, Civitas, Madrid, 1991.

BLASCO DÍAZ, J. L., Régimen jurídico de las propiedades particulares en el litoral, Tirant lo Blanch, Valencia, 1999.

BLASCO DÍAZ, J. L., "La distribución competencial en materia de costas", Revista d'Estudis Autonòmics i Federals, núm. 10, 2010, pp. 245-285.

CALERO RODRÍGUEZ, J. R., Régimen jurídico de las costas españolas, Aranzadi, Pamplona, 1995.

CARRO FERNÁNDEZ-VALMAYOR, J. L., FERREIRA FERNÁNDEZ, J. y NOGUEIRA LÓPEZ, A., La nueva regulación de las costas, INAP, Madrid, 2014.

CARRO FERNÁNDEZ-VALMAYOR, J. L., FERREIRA FERNÁNDEZ, J. y NOGUEIRA LÓPEZ, A. (coords.), La nueva regulación de las costas: actas del IX Congreso de la Asociación Española de Profesores de Derecho Administrativo, INAP, Madrid, 2014.

CASADO CASADO, L. y FUENTES I GASÓ, J. R., Medi ambient $i$ ens locals, CEDECS, Barcelona, 2008.

CASADO CASADO, L., "Las competencias ambientales de las entidades locales: luces y sombras tras la Ley $27 / 2013$, de 27 de diciembre, de racionalización y sostenibilidad de la Administración local", Revista Aranzadi de Derecho Ambiental, núm. 32, septiembre-diciembre 2015, pp. 201-283.

CHINCHILLA PEINADO, J. A., "La Ley 2/2013, de Protección y Uso Sostenible del Litoral, y el Real Decreto 876/2014, de 10 de octubre, por el que se aprueba el Reglamento General de costas", Revista de derecho urbanístico y medio ambiente, núm. 295, 2015, pp. 137-180.

DE VICENTE MARTÍNEZ, R. (coord.), Tratado de derecho ambiental, Tirant lo Blanch, Valencia, 2013. 
FERNÁNDEZ DE TROCÓNIZ, F., "El nuevo concepto de dominio público y sus consecuencias legales tras la reforma de la Ley de Costas", Torres-Fernández Nieto, J. J., Fernández de Trocóniz, F. C., Olano Espinosa, C., Menéndez Menéndez, A., González de Olano, G., Cancer Minchot, P. y Risquete, J. L., Comentario a la Ley 2/2013, de 29 de mayo, de Protección y Uso Sostenible del Litoral y de Modificación de la Ley 22/1988, de Costas, Thomson Reuters Aranzadi, Cizur Menor, 2014, pp. 87-132. FONT I LLOVET, T. y GALÁN GALÁN, A., "Racionalización y sostenibilidad de la Administración local: ¿es esta la reforma?”, Anuario del Gobierno Local 2012, Fundación Democracia y Gobierno Local, Instituto de Derecho Público, Barcelona, 2013.

FUENTES I GASÓ, J. R., “Consecuencias de la Ley 27/2013, de Racionalización y Sostenibilidad de la Administración Local en el régimen local de Cataluña”, Revista Vasca de Administración Pública, núm. 101, abril-mayo 2015, pp. 55-88.

GARCÍA PÉREZ, M., El derecho de costas en España, La Ley, Madrid, 2010.

GARCÍA PÉREZ, M., "La reforma de la Ley de Costas: un lobo con piel de cordero", El Cronista del Estado Social y Democrático de Derecho, núm. 31, 2012.

GARCÍA PÉREZ, M. y SANZ LARRUGA, F. J., "La distribución de competencias en el medio marino", Arana García, E. y Sanz Larruga, F. J. (dirs.), La ordenación jurídica del medio marino en España. Estudios sobre la Ley 41/2010, de protección del medio marino, Thomson Reuters, Cizur Menor, 2012.

GIFREU I FONT, J. y FUENTES I GASÓ, J. R. (dirs.), Règim jurídic dels governs locals de Catalunya, Tirant lo Blanch, Valencia, 2009.

GONZÁlEZ SALINAS, J., Régimen jurídico actual de la propiedad en las costas, Civitas, Madrid, 2000.

LÓPEZ PELLICER, J. A., "Los derechos adquiridos en zonas del demanio marítimoterrestre ante la nueva LC", REDA, núm. 68, octubre-diciembre 1990.

MARTÍNEZ CORDERO, J. R., "Clasificación y definiciones”, Pérez Gálvez, J. F. (dir.), El nuevo derecho de costas, Bosch, Barcelona, 2014, pp. 47-93.

MEILÁN GIL, J. L., “Comunidades autónomas y dominio público marítimo-terrestre. El proyecto de Ley de costas", Revista de Derecho Urbanístico y Medio Ambiente, núm. 108, 1988. 
MEILÁN GIL, J. L., "El concepto de dominio público marítimo-terrestre en el Proyecto de LC", Revista española de derecho administrativo, núm. 59, julio-septiembre, 1988.

MEILÁN GIL, J. L., "La Ley de costas y las competencias de las comunidades autónomas", Revista Gallega de Administración Pública, núm. 1, 1992.

MEILÁN GIL, J. L., "El dominio público natural y la legislación de costas", Revista de Administración Pública, núm. 139, enero-abril, 1996.

MENÉNDEZ MENÉNDEZ, A. y GONZÁLEZ DE OLANO, C., "La reforma y el régimen de las autorizaciones y concesiones”, Torres-Fernández Nieto, J. J., Fernández de Trocóniz, F. C., Olano Espinosa, C., Menéndez Menéndez, A., González de Olano, G., Cancer Minchot, P. y Risquete, J. L., Comentario a la Ley 2/2013, de 29 de mayo, de Protección y Uso Sostenible del Litoral y de Modificación de la Ley 22/1988, de Costas, Thomson Reuters Aranzadi, Cizur Menor, 2014, pp. 251-301.

MENÉNDEZ REXACH, A., "La configuración del dominio público marítimo-terrestre en la LC”, Estudios Territoriales, núm. 34, septiembre-diciembre 1990.

MENÉNDEZ REXACH, A., "La distribución de competencias en la Ley de costas y la gestión integrada del litoral”, Sanz Larruga, F. J. (dir.), Estudios sobre la ordenación, planificación y gestión del litoral: hacia un modelo integrado y sostenible, Observatorio del Litoral de la Universidad de A Coruña, A Coruña, 2009.

MENÉNDEZ REXACH, A., "Estudio preliminar. Esquema general del contenido de la Ley y problemas de aplicación”, Menéndez Rexach, A., Marcos Fernández, A., Rodríguez-Chaves Mimbrero, B., Bermúdez Sánchez, J. y Chinchilla Peinado, J. A., La Ley de Costas en la Jurisprudencia. Sentencias del Tribunal Constitucional, Ministerio de Medio Ambiente, y Medio Rural y Marino, Madrid, 2010.

MENÉNDEZ REXACH, A., "La nueva regulación de las costas: un giro hacia el dominio privado marítimo-terrestre", Carro Fernández-Valmayor, J. L., Ferreira Fernández, J. y Nogueira López, A. (coords.), La nueva regulación de las costas: actas del IX Congreso de la Asociación Española de Profesores de Derecho Administrativo, INAP, Madrid, 2014, pp. 13-55.

MENÉNDEZ REXACH, A., "Definición legal de la ribera del mar: novedades del Reglamento de Costas", Revista de derecho urbanístico y medio ambiente, núm. 295, 2015, pp. 17-44. 
MONTOYA FONT, F. J., Propuesta de metodología para la determinación del límite interior del dominio público marítimo-terrestre en algunos supuestos, Universitat Rovira i Virgili, Tarragona, 2013.

MORENO MOLINA, A. M., "Suspensión gubernativa de actos y acuerdos adoptados por las entidades locales. Cláusula antialgarrobico", Pérez Gálvez, J. F. y Alemán Monterreal, A. (coords.), Costas y urbanismo: el litoral tras la Ley 2/2013, de protección y uso sostenible del litoral y de modificación de la Ley de Costas, La Ley-El Consultor, Madrid, 2013.

MORENO MOLINA, A. M., “Otras servidumbres y limitaciones de propiedad”, Pérez Gálvez, J. F. (dir.), El nuevo derecho de costas, Bosch, Barcelona, 2014, pp. 625-664.

MUÑOZ MACHADO, S., "Reflexiones sobre la pretendida reforma del régimen local", Diario de Derecho Municipal, 10 de junio de 2013.

NOGUERA DE LA MUELA, B. y AGUIRRE I FONT, J. M., “Costas y urbanismo: de la Ley de costas al Proyecto de la ley de protección y uso sostenible del litoral y de modificación de la Ley 22/1988, de 28 de julio, de costas”, López Ramón, F. y Escartín Escudé, V. (coords.), Bienes públicos, urbanismo y medio ambiente, Marcial Pons, Madrid, 2013.

NÚÑEZ LOZANO, M. C., La reforma de la Ley de Costas de 2013, Tirant lo Blanch, Valencia, 2013.

OLANO ESPINOSA, C., "Servidumbre de protección y otras limitaciones legales", Torres-Fernández Nieto, J. J., Fernández de Trocóniz, F. C., Olano Espinosa, C., Menéndez Menéndez, A., González de Olano, G., Cancer Minchot, P. y Risquete, J. L., Comentario a la Ley 2/2013, de 29 de mayo, de Protección y Uso Sostenible del Litoral y de Modificación de la Ley 22/1988, de Costas, Thomson Reuters Aranzadi, Cizur Menor, 2014, pp. 217-249.

PARADA VÁZQUEZ, J. R., Derecho Administrativo III, Bienes Públicos. Derecho Urbanístico, Marcial Pons, Madrid, 2010.

PERALES MADUEÑO, F., "Legislación urbanística y legislación sectorial. Un ejemplo: proyecto de la Ley de costas", Revista de Derecho Urbanístico y Medio Ambiente, núm. 108, 1988, p. 123 y ss. 
PÉREZ GÁlVEZ, J. F. y ALEMÁN MONTERREAL, A. (coords.), Costas y urbanismo: el litoral tras la Ley 2/2013, de protección y uso sostenible del litoral y de modificación de la Ley de Costas, La Ley-El Consultor, Madrid, 2013.

QUINTANA LÓPEZ, T. (dir.), La reforma del régimen local: comentario a la Ley 27/2013, de 27 de diciembre, de racionalización y sostenibilidad de la Administración Local, Tirant lo Blanch, Valencia, 2014.

RIVAS ANDRÉS, R., "Las marinas y el nuevo “estacionamiento náutico" como derecho real, legal y administrativo en la reformada Ley de Costas", Diario La Ley, núm. 8214, 2013.

RODRÍGUEZ BEAS, M. y FUENTES I GASÓ, J. R., "La organización territorial del Estatuto de 2006 y el impacto de la Ley 27/2013, de Racionalización y Sostenibilidad de la Administración Local en la interiorización del régimen local de Cataluña", García Rubio, F. (dir.), Análisis de las repercusiones de la reforma local sobre la organización, competencias y servicios de las entidades locales, INAP Investiga, Madrid, julio 2015, pp. 511-568.

RODRÍGUEZ GONZÁLEZ, M. P., El dominio público marítimo-terrestre: titularidad y sistema de protección, Marcial Pons, Madrid, 1999.

RODRÍGUEZ LÓPEZ, P., Comentarios a la LC, Doctrina y Jurisprudencia, Dijusa, Madrid, 2003.

SANZ LARRUGA, F. J., "La reforma de la Ley de Costas o la apertura de la Caja de Pandora", Revista Aranzadi de Derecho Ambiental, núm. 25, 2013, pp. 11-20.

SANZ LARRUGA, F. J., "Temores y expectativas ante la reforma de la ley de Costas", López Ramón, F. (coord.), Observatorio de Políticas Ambientales 2013, Thomson Reuters-Aranzadi, Cizur Menor, 2013.

SANZ LARRUGA, F. J., "La reforma de la Ley de Costas o la puesta en valor económico del litoral", López Ramón, F. (coord.), Observatorio de Políticas Ambientales 2014, Thomson Reuters-Aranzadi, Cizur Menor, 2014, pp. 463-485.

TORNOS MAS, J., “Tipologia de les competències. El seu abast funcional: els articles 110 a 112", Revista Catalana de Dret Públic. Especial Sentència 31/2010 del Tribunal Constitucional, sobre l'Estatut d'Autonomia de Catalunya de 2006, 2010, pp. 288-294. 
TORRES-FERNÁNDEZ NIETO, J. J., FERNÁNDEZ DE TROCÓNIZ, F. C., OLANO ESPINOSA, C., MENÉNDEZ MENÉNDEZ, A., GONZÁLEZ DE OLANO, G., CANCER MINCHOT, P. y RISQUETE, J. L., Comentario a la Ley 2/2013, de 29 de mayo, de Protección y Uso Sostenible del Litoral y de Modificación de la Ley 22/1988, de Costas, Thomson Reuters Aranzadi, Cizur Menor, 2014, pp. 251-301.

TOSCANO GIL, F., "El nuevo sistema de competencias municipales tras la Ley de racionalización y sostenibilidad de la administración local: competencias propias y competencias distintas de las propias y de las atribuidas por delegación", Revista española de derecho administrativo, núm. 165, 2014, pp. 285-320.

VELASCO CABALLERO, F., "Nuevo régimen de competencias municipales en el Anteproyecto de Racionalización y sostenibilidad de la Administración Local”, Anuario de Derecho Municipal, núm. 6, pp. 23-60.

VILLALBA PÉREZ, F., “Concesiones y autorizaciones de dominio público marítimoterrestre en el Real Decreto 876/2014, de 10 de octubre, por el que se aprueba el Reglamento General de la Ley de Costas”, Pérez Gálvez, J. F. (dir.), El nuevo derecho de costas, Bosch, Barcelona, 2014, pp. 665-743.

VILLANUEVA CUEVAS, A., PUNZÓN MORALES, J. y SÁNCHEZ RODRÍGUEZ, F., "La protección medioambiental de las costas", Ortega Álvarez, L. I., Alonso García, M. C. y Rodríguez González, M. P., El dominio público marítimo-terrestre: titularidad y sistemas de protección, Marcial Pons, Madrid, 1999.

ZAFRA VÍCTOR, M., "Reordenación de las competencias municipales, entre la eficacia y democracia", Forcadell Esteller, X. y Sabaté Vidal, J. M. (coords.), La reforma local. Reptes i oportunitats davant dels projectes de reforma del règim local impulsats pel govern estatal $i$ el govern de la Generalitat, Diputación de Barcelona, 2013, pp. 46-60.

ZAMORANO WISNES, J., La ordenación del litoral. Una propuesta de gestión integrada, La Ley, Madrid, 2013. 